\title{
O/A/AA
}

\section{Multi-Disciplinary Shape Optimization of Missile Fin Configuration Subject to Aerodynamic Heating}

\begin{tabular}{|r|l|}
\hline Journal: & Journal of Spacecraft and Rockets \\
\hline Manuscript ID & $2019-06-A 34575$ \\
\hline Manuscript Type: & Full Paper \\
\hline Author: & 23-Jun-2019 \\
\hline Complete List of Authors: & $\begin{array}{l}\text { Vidanović, Nenad; University of Belgrade, Faculty of Transport and } \\
\text { Traffic Engineering } \\
\text { Rasuo, Bosko; University of Belgrade, Aeronautical Department, Faculty } \\
\text { of Mechanical Engineering } \\
\text { Kastratović, Gordana; University of Belgrade, Faculty of Transport and } \\
\text { Traffic Engineering } \\
\text { Grbović, Aleksandar; University of Belgrade, Aeronautical Department, } \\
\text { Faculty of Mechanical Engineering } \\
\text { Puharić, Mirjana; UNION - Nikola Tesla University, FITI } \\
\text { Maksimović, Katarina; City Administration of the City of Belgrade, Water } \\
\text { Administration, Sector for Water Management }\end{array}$ \\
\hline Subject Index Category: & $\begin{array}{l}\text { INTERDI0 Multidisciplinary Design Optimization < 40000 } \\
\text { STRUCTURAL MECHANICS AND MATERIALS, 81300 Thermal Effects }< \\
\text { 80000 STRUCTURAL MECHANICS AND MATERIALS }\end{array}$ \\
\hline
\end{tabular}

\section{SCHOLARONE \\ Manuscripts}




\title{
Multi-Disciplinary Shape Optimization of Missile Fin Configuration Subject to Aerodynamic Heating
}

\author{
Nenad Vidanović, ${ }^{*}$ Boško Rašuo, ${ }^{\dagger}$ Gordana Kastratović,, and Aleksandar Grbović $\$$ \\ University of Belgrade, 11000 Belgrade, Serbia \\ Mirjana Puharić** \\ UNION - Nikola Tesla University, 11000 Belgrade, Serbia \\ and \\ Katarina Maksimovići ${ }^{\dagger}$ \\ City Administration of the City of Belgrade, 11000 Belgrade, Serbia
}

\footnotetext{
* Assistant Professor, Faculty of Transport and Traffic Engineering, Vojvode Stepe 305; n.vidanovic@sf.bg.ac.rs (Corresponding Author).

$\dagger$ Full Professor, Faculty of Mechanical Engineering, Kraljice Marije 16, Senior Member AIAA; brasuo@mas.bg.ac.rs.

$\$$ Full Professor, Faculty of Transport and Traffic Engineering, Vojvode Stepe 305; g.kastratovic@sf.bg.ac.rs.

§ Associate Professor, Faculty of Mechanical Engineering, Kraljice Marije 16; agrbovic@mas.bg.ac.rs.

** Full Professor, FITI, Jurija Gagarina 149a; mirjana.puharic@fpsp.edu.rs.

† Research Associate, Water Administration, Sector for Water Management, Trg Nikole Pašića 1; kmaksimovic@mts.rs.
} 
The main goal of this paper is to expand previously conducted study and consequently to upgrade proposed multi-modular numerical framework developed for fluid-structure interaction simulation (FSI) and multi-disciplinary design optimization (MDO) purposes, in a manner that thermal-structure interaction is observed and implemented into established numerical framework. Upgraded and considerably improved algorithm was used for MDO of the short-range ballistic missile (SRBM) model. Due to its high-speed exploitation regimes, this aircraft model was selected for the purpose of numerical modeling and optimization of aerodynamically heated structure. The present study concerns with wider observation of critical multi-point flight conditions and represents more realistic scenario which indicates this study as one more contribution in a scope of fluid-thermal-structure interaction (FTSI) numerical modeling and optimization. With respect to predefined objectives and constrains, multi-disciplinary shape optimization of the fin structure was resulted in overall improvement of missile initial performances. Also, aerothermally-induced critical responses of the fin structure was prevented. Numerical modeling of FSI/FTSI and MDO within an industry-accepted design tool was resulted in powerful monolithic environment which with adopted multi-point regimes and multi-criteria settings was used for aerodynamic-thermal/structural optimization. The obtained results were compared with the results from the previous study conducted without thermal effects.

\section{Nomenclature}

$$
\begin{aligned}
\rho & =\text { density, } \mathrm{kg} / \mathrm{m}^{3} \\
e & =\quad \text { internal energy, } \mathrm{J} \\
e_{t} & =\text { total energy, } \mathrm{J} \\
p & =\text { pressure, } \mathrm{Pa} \\
\mu & =\quad \text { viscosity coefficient, }(\mathrm{N} \cdot \mathrm{s}) / \mathrm{m}^{2} \\
k & =\text { thermal conductivity, } \mathrm{W} /(\mathrm{m} \cdot \mathrm{K}) \\
\gamma & =\quad \text { specific heat ratio, }- \\
T & =\text { temperature, } \mathrm{K}
\end{aligned}
$$


$u=$ velocity component of the fluid in the $x$ direction, $\mathrm{m} / \mathrm{s}$

$v=$ velocity component of the fluid in the $y$ direction, $\mathrm{m} / \mathrm{s}$

$w=$ velocity component of the fluid in the $z$ direction, $\mathrm{m} / \mathrm{s}$

$\tau_{i j} \quad=\quad$ viscous stress tensor components, $\mathrm{Pa}$

$\mathrm{V}=$ velocity, $\mathrm{m} / \mathrm{s}$

$q_{i}=$ heat flux vector components, $\mathrm{W} / \mathrm{m}^{2}$

$\alpha=$ coefficient of thermal expansion, $\mathrm{K}^{-1}$

$E \quad=\quad$ Young's modulus, GPa

$v \quad=\quad$ Poisson's ratio, -

\section{Introduction}

W UMERICAL modeling of aerothermoelasticity presents prevailing task in high-speed flow design and optimization of missiles and aerospace vehicles. Numerical optimization procedure regarding aerothermoelastic phenomenon in high-speed flows presents an essential consideration for preventing structural failure. The interaction between the aerodynamically-heated elastic structure and the aerodynamic forces acting on it, and consequently its resulting behavior during the exploitation process, present the subjects of the aerothermoelastic analysis. For the purposes of satisfying all conflicted requirements and multi-criteria problems numerical MDO techniques have become paramount tool which can provide globally optimal solution.

As a result of high-speed flights, aerodynamic heating of supersonic and hypersonic regimes have been under intensive investigations over many years.

The paper [1] deals with the basic concept of calculation procedure of aerodynamic heating and discusses the approximate methods which have been used to calculate turbulent heating rates for a flat-plate case. Aerodynamic heating on the fin leading edges of a sounding rocket flying at hypersonic speed has been evaluated in [2]. In this study fluid flow properties have been obtained in an approximate manner, whereas the convective heat flux has been calculated from classical relationships provided in the literature. In paper [3] convection coefficients and heat fluxes due to aerodynamic heating on critical surfaces of hypersonic vehicle are obtained analytically. The study [4] focuses on evaluation of the nose tip and fin surface heat fluxes of supersonic projectile, and its fin sweep angle affection on the heat flux intensity and surface distributions. Here, a numerical approach has been developed based on 3D RANS and 2D coupled aero-heating/conduction computations in order to understand and predict severe aero- 
thermal environment. Experimental and numerical study on aerodynamic heating characteristics of blunted waverider has been conducted in [5]. The influence of aero-heating effects on the nose region, leading edge, upper and lower surface has been studied. Numerical algorithm has been developed based on 3D compressible N-S equations. In paper [6] numerical algorithm with SST turbulent model has been used to simulate effects of Mach number on nose-tip during supersonic flight conditions. Authors in publication [7] have presented detailed review of most cited papers in the field of high-speed flow research regarding aerothermodynamics. Also, authors in [8] and [9] have developed two different well-predictive numerical N-S solvers for the purpose of numerical observation of thermal effects on surfaces of high-speed aircrafts.

The effects of aerodynamic heating on supersonic and hypersonic vehicle components impose the necessity of coupling procedure between aerodynamic, thermal and structural analysis.

Aeroelastic and aerothermoelastic review paper [10] observes different approximate and robust methods and their coupling approaches between calculation domains but also emphasizes the necessity of accurate and efficient CFD-based modeling of aerodynamic heating phenomenon. A two-dimensional finite element approach for integrated fluid-thermal-structural analysis of aerodynamically heated structures is described in [11]. This approach provides better understanding of simulated coupled fields and represents one of the first studies which enables significant reduction of human and computational efforts. Authors in [12] have proposed simplified coupling algorithm between LORE CFD code and MSC Nastran finite element-based code for the purpose of numerical modeling fluid-structure thermal simulations for hypersonic flow-field. In order to study the importance of coupled field problems the authors in [13] deal with different degrees of aerothermoelastic coupling. The fluid-thermalstructure interaction with the purpose of materials thermal protection investigation in hypersonic flow field has been studied in [14]. FLUENT has been used to compute the surface heat flux while LS-DYNA has been used to simulate the thermal structural response of the thermal protection material. Those commercial codes have been loosely coupled with user-defined programming to achieve the solution. The authors in publication [15] have adopted fully coupled two-way FTSI procedure which then has been applied on a 2D fin in hypersonic cruise flight. In [16], FTSI approach based on the coupling of different commercial software (STAR-CCM+ and ABAQUS) has been conducted. The approach is preliminarily applied to investigate structural, fluid dynamic and aero-thermal behavior of a flexible hypersonic vehicle. In $[17,18]$, MpCCI framework has been used to implement data exchange process between FLUENT and Abacus software for the purpose of loosely-coupled fluid-thermal analysis of the spiked blunt 

efficient and economic way. In [20], for the purpose of FTSI phenomena simulation, HyCCD environment has been used to couple custom HyCFD code and commercial ANSYS APDL code for the purpose of thermal protection design of hypersonic vehicles.

Many researchers have focused their efforts in developing different optimization frameworks in which supersonic and hypersonic vehicles have been studied.

The paper [21] presents aerodynamic shape optimization of the nose cone for supersonic and hypersonic flight conditions. The optimization process has been driven by a surrogate-based evolutionary algorithm and the numerical aerodynamic calculations have been conducted in ANSYS CFX commercial code. Single-point optimization at each supersonic and hypersonic flow has been effectively performed as a single-objective study. Paper [22] deals with the aerodynamic shape optimization of the hypersonic vehicle. Optimization problem has been defined as both singleobjective and multi-objective criterion driven by two evolutionary algorithms embedded within iSIGHT software. Hypersonic aerodynamic quantities have been approximately modeled using the Newtonian theory of fluid flow. Authors in [23] have proposed the optimal design of hypersonic vehicle which has been achieved by using an accurate surrogate-based optimization method. Numerical single-discipline optimization problem has been solved in DIRECT global optimizer.

The numbers of studies that are dealing with different multi-discipline optimization frameworks and formulations of missiles are limited, due to the complexity of exploitation regimes of such aircrafts.

In paper [24] an efficient aerodynamic-structural design tool for missile fin configuration shape optimization has been developed. Subsonic (SUBDL) and supersonic (SUPDL) panel method-based modules have been employed for aerodynamic calculations while structural analysis has been conducted in finite element code CNEVAL-FEMODS. Powell's Conjugate Directions search algorithm has been selected as an optimization algorithm. Authors in [25] have been proposed modular response surface-based multi-disciplinary feasible optimization framework driven by the gradient-based optimizer. Their intention has been to show that proposed MDO formulation can be successfully applied on solving various practical large-scaled industrial problems. The established single-objective study has been effectively tested on a missile design. A conceptual design tool EXCON has been developed as a missile multimodular optimization framework [26]. Within this framework, Missile DATCOM semi-empirical code has been 
used for aerodynamic coefficients prediction while quazzy multi-objective optimization process has been driven by MATLAB Genetic Algorithm Toolbox. The Missile DATCOM has been also used in publication [27]. It has been linked with a real coded Adaptive Range Genetic Algorithm, in order to develop a single-objective shape optimization (canard and tail geometry) system capable of global range maximization. A multi-objective surrogatebased optimization process of supersonic missile canard and tail surfaces has been performed in [28]. The optimization procedure has been driven by NSGA-II algorithm, while the CART3D CFD numerical solver and the NEAR MISL3 semi-empirical aero-predictive code have been used for aerodynamic data prediction. In [29-32] the authors have been used the evolutionary-based algorithms, mostly genetic algorithms, for a wide range of missile performances preliminary design optimization, where semi-empirical code AeroDsn has been employed for aerodynamic prediction analysis, and because of the complexity of the problems, series of different codes have been used for performance simulations.

It can be observed that none of above cited literature regarding optimization have considered thermal effects because there is a limited number of such studies.

Multi-disciplinary topology optimization of a lifting surface in high-speed flow has been carried out in [33]. Presented aero-thermo-structural optimization design has been defined as a single-objective and single-point study based on surrogate modeling and global optima searching. For the purpose of MDO of hypersonic wing structure authors in paper [34] have proposed modular framework which integrates Argo CFD code, MSC Nastran finite element-based code and HyperSizer optimization software. The optimization framework has been defined as a single-point and single-objective study with discreet optimized parameters. Within this framework MpCCI code coupling interface has been used for data transferring process between Agro and Nastran codes. Single-point multidisciplinary topology optimization of the hypersonic wing structure has been conducted by the authors in [35]. In this paper created modular framework is controlled by MATLAB which integrates AGPS code as a mesh modeler, Tranair as a CFD-based code, MSC Nastran as a finite element-based code, Conjugate heat transfer analysis module and BESO evolutionary algorithm for optimization process. The robust multi-disciplinary single-point and singleobjective optimization framework for thermal protection material thickness of hypersonic wings driven by genetic algorithm has been proposed in [36]. Within this integrated framework aerodynamic analysis has been conducted by shock-expansion and local piston theory, aerodynamic heating has been modeled by Eckert's reference enthalpy method while structural analysis has been conducted using finite element method. 
As it can be seen, even if the optimization studies take into consideration thermal effects they are addressed only to single-point or single-objective problem and some of them concern with topology optimization or model fluid and structural domains with approximate methods. Also, the researchers are still facing the same problem, because the proposed optimization frameworks are either based on uniquely developed codes and environments, or they are based on coupling of diverse commercial software. All this causes complications regarding the availability of these frameworks, their use, and cause coupling, training and finally costing problems. In general, numerical modeling of the boost regime, as critical ascend phase, which is also extremely multi-point optimization problem, has been neglected by the researchers, so there is a lack of these studies in the literature. This study, which addresses a relevant aspect in missile aerothermoelasticity, represents, among others, an effort to fulfill this gap, since this type of complex and robust numerical analysis has never been performed on missile structures.

This paper presents a well-established multi-modular optimization-based and experimentally-supported numerical framework created within an industry-accepted design tool. Within this framework numerical modeling of FSI/FTSI was carried out through closely coupled fluid and structural computational domains. Proposed multidisciplinary feasible method represents a single level method driven by an embedded multi-objective genetic algorithm supported by surrogate modeling techniques. Established optimization framework improves overall design processes and ensures significantly improved missile structure where safety and reliability in extreme exploitation phases are satisfied. It represents very robust multi-point optimization formulation with 4 objectives and 14, i.e. 15 constraints forced by different priority and handling levels. Additionally, simplification of the conceptual design process with time/cost reduction was achieved, too.

\section{Numerical Multi-Modular Optimization Framework}

The algorithm of multi-modular design optimization framework is presented in Fig.1. This framework enables numerical modeling of aerodynamics, static aeroelastic and static aerothermoelastic, as well as aerodynamicstructural and aerodynamic-thermal/structural numerical optimization. This algorithm depicts data flows and the organization of a presented numerical framework. This automated environment is composed of two sub environments. The first denoted as „Aerodynamic-structural and aerodynamic-thermal/structural environment” is accountable for aerodynamic, FSI or FTSI numerical modeling, and the second one is the surrogate-based optimization module. 


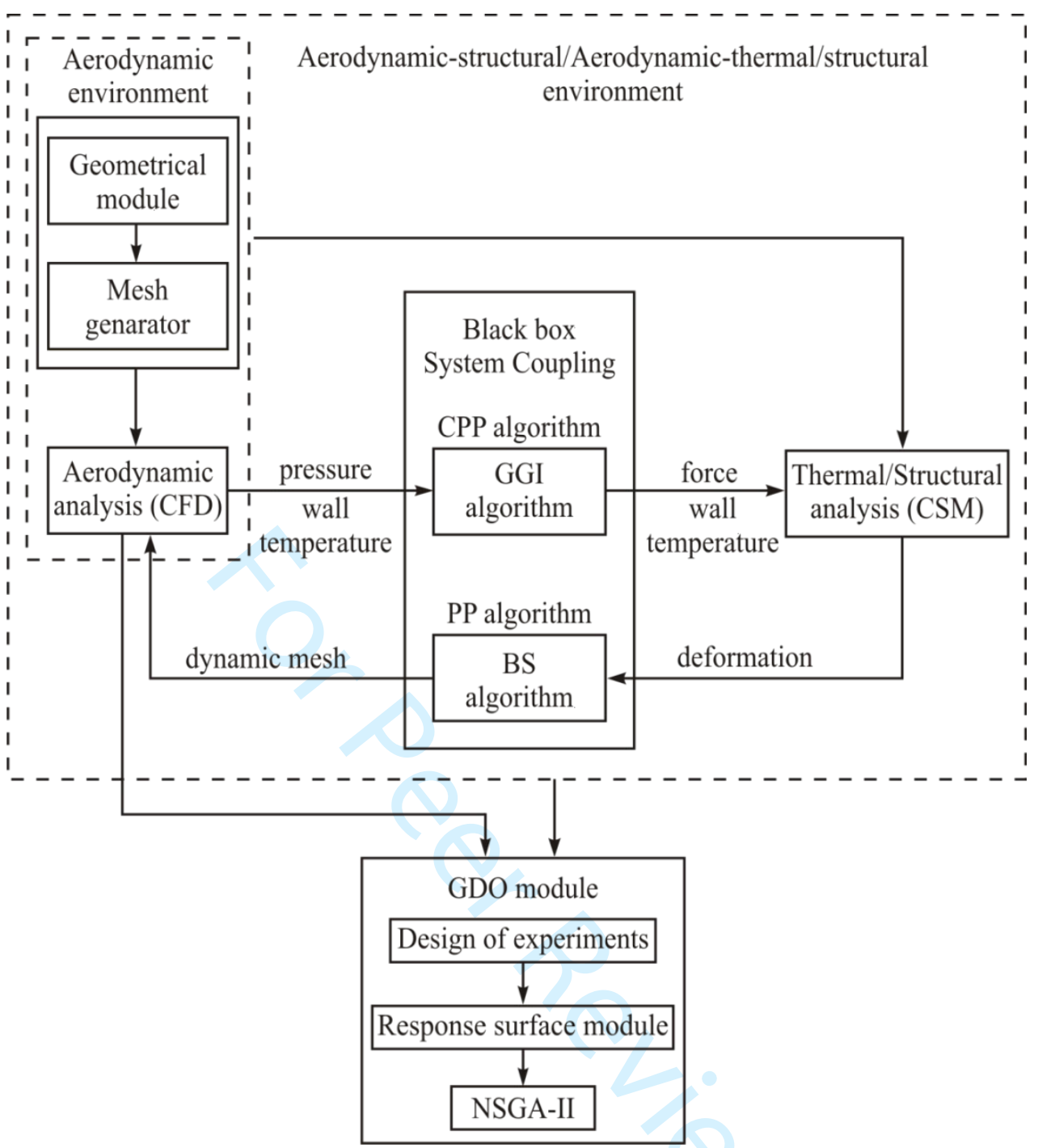

Fig. 1 Data flow algorithm for established multi-modular framework

The 3D parametric model and the fluid domain were created in a parametric feature-based modeler [37] designed to be used as a geometry creator or editor (Geometrical module in Fig. 1).

Modeled fluid and structural domains delivered by CAD module were discretized by highly automated mesh generator [38] (Mesh generator in Fig. 1).

The finite volume-based flow solver used in this study was the ANSYS Fluent [39, 40] (Aerodynamic analysis (CFD) module in Fig. 1). For the purpose of FSI and FTSI simulations, more suitable Pressure-based type solver with coupled scheme was used. For the purpose of numerical calculation of the turbulent flow Menter's SST $k-\omega$ model was selected [41-46]. The entire system of three-dimensional compressible Navier-Stokes equations is described by Eq. (1) [5]: 


$$
\frac{\partial}{\partial t} Q+\frac{\partial}{\partial x}\left(F_{i}-F_{v}\right)+\frac{\partial}{\partial y}\left(G_{i}-G_{v}\right)+\frac{\partial}{\partial z}\left(H_{i}-H_{v}\right)=0
$$

where the column vectors $Q, F, G$ and $H$ are defined as:

$$
\left.\begin{array}{c}
Q=\left\{\begin{array}{c}
\rho \\
\rho u \\
\rho v \\
\rho w \\
\rho e
\end{array}\right\} \quad F_{i}=\left\{\begin{array}{c}
\rho u \\
\rho u^{2}+p \\
\rho v u \\
\rho w u \\
\rho u e_{t}+p u
\end{array}\right\} \quad F_{v}=\left\{\begin{array}{c}
0 \\
\tau_{x x} \\
\tau_{x y} \\
\tau_{x z} \\
0 \\
q_{x}+u \tau_{x x}+v \tau_{x y}+w \tau_{x z}
\end{array}\right\} \quad G_{i}=\left\{\begin{array}{c}
\rho v \\
\rho u v \\
\rho v^{2}+p \\
\rho w v \\
\rho v e_{t}+p v
\end{array}\right\} \\
G_{v}=\left\{\begin{array}{c}
\rho w \\
\rho u w \\
\rho v w \\
\rho w^{2}+p \\
\rho w e_{t}+p w
\end{array}\right\} \quad H_{v}=\left\{\begin{array}{c}
0 \\
\tau_{y z} \\
\tau_{z x} \\
\tau_{z y} \\
\tau_{z z} \\
q_{y}+u \tau_{y x}+v \tau_{y y}+w \tau_{y z}
\end{array}\right\} \quad H_{z}+u \tau_{z x}+v \tau_{z y}+w \tau_{z z}
\end{array}\right\}
$$

in which

$$
\begin{aligned}
& \tau_{x x}=2 \mu \frac{\partial u}{\partial x}-\frac{2}{3} \mu \nabla \cdot \mathbf{V} \quad \tau_{y y}=2 \mu \frac{\partial v}{\partial y}-\frac{2}{3} \mu \nabla \cdot \mathbf{V} \quad \tau_{z z}=2 \mu \frac{\partial w}{\partial z}-\frac{2}{3} \mu \nabla \cdot \mathbf{V} \\
& \tau_{x y}=\tau_{y x}=\mu\left(\frac{\partial u}{\partial y}+\frac{\partial v}{\partial x}\right) \quad \tau_{y z}=\tau_{z y}=\mu\left(\frac{\partial v}{\partial z}+\frac{\partial w}{\partial y}\right) \quad \tau_{z x}=\tau_{x z}=\mu\left(\frac{\partial u}{\partial z}+\frac{\partial w}{\partial x}\right) \\
& q_{x}=k \frac{\partial T}{\partial x} \quad q_{y}=k \frac{\partial T}{\partial y} \quad q_{z}=k \frac{\partial T}{\partial z} \quad e_{t}=\frac{p}{(\gamma+1) \rho}+\frac{1}{2}\left(u^{2}+v^{2}+w^{2}\right)
\end{aligned}
$$

The column vector $Q$ is the conservation vector flux, where $F, G$ and $H$ are called the flux terms of $x, y$ and $z$ directions, respectively. The flux terms $F_{i}, G_{i}$ and $H_{i}$ present relative inviscid terms, while the flux terms $F_{v}, G_{v}$ and $H_{v}$ present relative viscid terms. All other relevant information regarding methods, formulations, schemes, discretizations and boundary conditions can be found in [47].

The Sparse direct solver, embedded in the finite element method-based structural module $[48,49]$ was used for the solutions of linear system of equations (Thermal/Structural analysis (CSM) module in Fig. 1). The equilibrium equation for three dimensional static analysis problem was derived from the principle of minimum potential energy in which stress-strain relationship of the structure subjected to temperature rise is expressed by the system of equations (2), similar as in [50]: 


$$
\begin{aligned}
& \varepsilon_{x}=\frac{\partial u}{\partial x}=\frac{1}{\mathrm{E}}\left[\sigma_{\mathrm{x}}-v\left(\sigma_{y}+\sigma_{z}\right)\right]+\alpha \Delta T, \quad \gamma_{\mathrm{xy}}=\frac{\tau_{x y}}{G} \\
& \varepsilon_{y}=\frac{\partial v}{\partial y}=\frac{1}{\mathrm{E}}\left[\sigma_{\mathrm{y}}-v\left(\sigma_{z}+\sigma_{x}\right)\right]+\alpha \Delta T, \quad \gamma_{\mathrm{yz}}=\frac{\tau_{y z}}{G} \\
& \varepsilon_{z}=\frac{\partial w}{\partial z}=\frac{1}{\mathrm{E}}\left[\sigma_{\mathrm{z}}-v\left(\sigma_{x}+\sigma_{y}\right)\right]+\alpha \Delta T, \quad \gamma_{\mathrm{zx}}=\frac{\tau_{z x}}{G}
\end{aligned}
$$

where $\varepsilon_{x}, \varepsilon_{y}$ and $\varepsilon_{z}$ are the normal strains, $\gamma_{x y}, \gamma_{y z}$ and $\gamma_{z x}$ are the shear strains, $u, v$ and $w$ are the displacements, $\sigma_{x}, \sigma_{y}$ and $\sigma_{z}$ are the normal stresses, $\tau_{x y}, \tau_{y z}$ and $\tau_{z x}$ are the shear stresses and $\Delta T$ is the temperature difference.

The stresses can be defined as:

$$
\{\sigma\}=[D]\left(\{\varepsilon\}-\left\{\varepsilon_{0}\right\}\right)
$$

where the matrix $[D]$ is defined as:

$$
[D]=\frac{E}{(1+v)(1-2 v)}\left[\begin{array}{cccccc}
1-v & v & v & 0 & 0 & 0 \\
v & 1-v & v & 0 & 0 & 0 \\
v & v & 1-v & 0 & 0 & 0 \\
0 & 0 & 0 & \frac{(1-2 v)}{2} & 0 & 0 \\
0 & 0 & 0 & 0 & \frac{(1-2 v)}{2} & 0 \\
0 & 0 & 0 & 0 & 0 & \frac{(1-2 v)}{2}
\end{array}\right]
$$

and strains generated by the temperature difference $\left\{\varepsilon_{0}\right\}$ are given by:

$$
\left\{\varepsilon_{0}\right\}=\left\{\begin{array}{c}
\varepsilon_{x 0} \\
\varepsilon_{y 0} \\
\varepsilon_{z 0} \\
\gamma_{x y 0} \\
\gamma_{y z 0} \\
\gamma_{x z 0}
\end{array}\right\}=\left\{\begin{array}{c}
\alpha \Delta \mathrm{T} \\
\alpha \Delta \mathrm{T} \\
\alpha \Delta \mathrm{T} \\
0 \\
0 \\
0
\end{array}\right\}
$$

The equilibrium equations of the overall structure is expressed as:

$$
[K]^{e}\{\delta\}^{e}=\left\{F^{m}\right\}+\left\{F^{t h}\right\}
$$

where $[K]^{e}$ presents element stiffness matrix, $\{\delta\}^{e}$ presents unknown nodal deflections, $\left\{F^{m}\right\}$ is the mechanical load vector and $\left\{F^{\text {th }}\right\}$ is the thermal load vector.

The coupling module [51] represents a special feature of multi-modular framework (System Coupling module in Fig. 1). This module enables coupling, control and synchronization of the selected solvers in order to accomplish 
numerical simulation of so-called two-way FSI or FTSI which consequently allows realistic modeling of computational aeroelasticity and aerothermoelasticity phenomena. As a result of export/import mechanism, dynamic mesh model [52, 53] supported by the spring-based smoothing technique was used to ensure mesh moving/deforming behavior of the fluid domain. Profile preserving (PP) algorithm and Conservative profile preserving (CPP) algorithm as a data transfer algorithms represent combinations of mapping and interpolation algorithms that are used by the coupling module. As a mapping algorithms embedded in data transfer algorithms, Bucket surface (BS) algorithm [54] and General grid interface (GGI) algorithm [55] are employed. The interpolation algorithm provides target node values using the source data and maps weights generated by the mapping algorithms.

The optimization environment [56], so-called Goal driven optimization module (GDO), is composed of the Design of experiments technique (DOE), Response surface method (RSM) [57] and Multi-objective genetic algorithm (MOGA) [58] (GDO module in Fig. 1). Central composite design defined with the face-centered design type and the standard template type was selected as a DOE type. The standard response surface type - full 2nd order polynomials was applied to provide the design points. As a global optimizer, MOGA represents a hybrid variant of the NSGA-II based on Pareto ranking and controlled elitism concepts [59-64]. The decision support process represents weighted, aggregation-based and goal-based design ranking technique [56]. The candidate points are ranked based on general Eq. (6):

$$
\Phi \equiv \sum_{i=1}^{n} w_{i} N_{i}+\sum_{j=1}^{m} w_{j} M_{j}
$$

where $w_{i}$ and $w_{j}$ are weights. Based on priority, missile fitness functions were weighted by 1.000 , as a high priority objectives, and fin mass was weighted by 0.333 , as a lower priority objective. At the same time constraint importance to be lower was assigned to fin mass, fin area and to centre of pressure for $M=4.0$ whereas constraint importance to be higher was assigned to aerodynamic efficiencies, differences between vertical deflections at positions 7 and 3 and to maximum deflections of the fin tips at the same positions 7 and 3. Also, constraint handling to be strict was assigned to all defined constraints. $N_{i}$ and $M_{j}$ are normalized objectives for input and output parameters. 


\section{Numerical Accuracy}

Establishing of numerical accuracy was conducted by several separate verification and validation (V\&V) studies regarding available aerodynamic and structural experiments. All relevant details about accomplished V\&V studies can be found in $[47,65,66]$, but it is necessary to emphasize few things in this section thus making further text more understandable.

The wind tunnel SRBM model and the real-sized experimental fin model have been separately developed and manufactured for scientific, codes $\mathrm{V} \& \mathrm{~V}$ procedure and internal experimental testing and calibration purposes in Military Technical Institute in Belgrade (VTI). Based on the fact that missile wind tunnel model and real-sized fin model designed for experimental strength analysis are experimental models each adapted for corresponding experimental test section dimensions (Fig. 2 and Fig. 3), scaling procedure had to be done and it is discussed in next subsection. SRBM model with interchangeable nose and fin sections is similar to modified basic finner missile (MBFM) model [67].

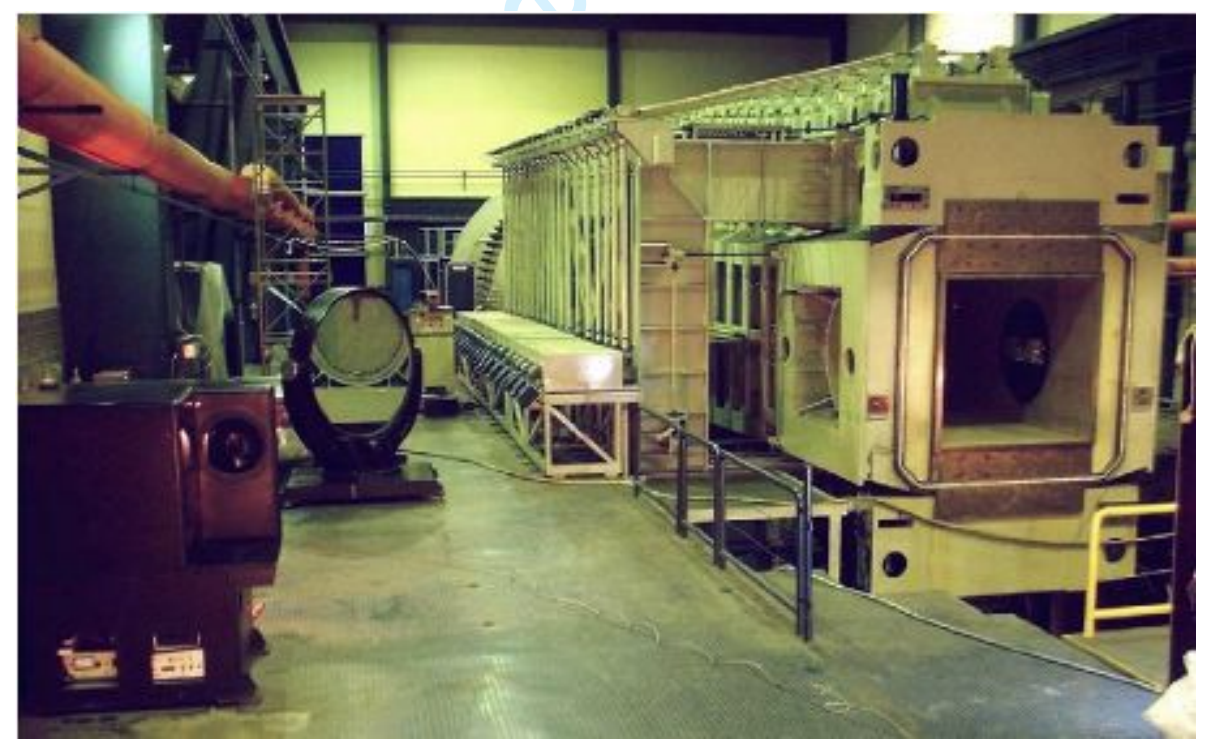

Fig. 2 a) The T-38 tri-sonic blow-down pressurized test facility with test section 


\section{A. The 2-way FTSI Prediction of the Scaled Model}

The strategy of modeling well-predictive numerical simulations for the scaled model was based on the assumption that if the V\&V of CFD prediction regarding missile wind tunnel model were satisfactorily done, the 
CFD results of the scaled model are credible as well. Numerical settings used for the simulations of the scaled model are proportional to the ones established for the experimental models and also with the same dicretization of fluid and structural domain. Numerical accuracy of coupled analyses which were taken part in different stages within the overall optimization procedure, after conducted V\&V studies, are established on the assumption that if the numerical prediction of the missile model and its fin model are quantitatively good enough, then the numerical prediction of the scaled missile model is good enough, too.

As an exploitation regime nominated to be a critical, $M=2.3$ with alpha $=5^{\circ}$ affects maximal allowable deflections [47]. Consequently, these deflections were selected to be one of the constraints within different optimization problems. After conducted necessary scaling process of the wind tunnel model, FTSI numerically simulated results for critical flight condition $\left(M=2.3\right.$ and alpha $\left.=5^{\circ}\right)$ indicated that the lift force on horizontal fin is noticeably increased from $F l_{f i n}=3608.01[\mathrm{~N}]$ (corresponding drag force $F d_{f \text { in }}=529.21[\mathrm{~N}]$ ), which is the value simulated for the fin only, to $F l_{f i n}=4520.5[\mathrm{~N}]$ (corresponding drag force $F d_{f i n}=591.13[\mathrm{~N}]$ ), which is the value simulated for the whole scaled model and thus influenced by the interference effects. This increased lift force together with the aerodynamic heating effect cause the increase of the initial deflections simulated for the fin only, from $u_{7}=0.01833[\mathrm{~m}]$ to $u_{7}=0.03052[\mathrm{~m}]$, at the position 7 , and from $u_{3}=0.01622[\mathrm{~m}]$ to $u_{3}=0.02573$ [m], at the position 3. In the previously published aerodynamic-structural study [47], experimentally measured deflections exited by the applied inertial loads and calculated aerodynamic load were chosen to be the constraints within the optimization problem because of the theoretical/conceptual requirement, but mentioned study was conducted without thermal influence. Once again, these deflections with the measured values of $u_{7}=0.01925[\mathrm{~m}]$ and $u_{3}=$ $0.01815[\mathrm{~m}]$ correspond to the regime defined with $M=2.3$ and with the angle of attack of $5^{\circ}$ [47], but they are not thermally affected. So, because of the strong influence of the aerodynamic heating on the fin responses, which is one of the major topics of the current study, previously measured deflection values had to be replaced with thermally affected ones. After conducted numerical simulation of the fin structure with thermal influence, calculated values of $u_{7}=0.02370[\mathrm{~m}]$ and $u_{3}=0.02058[\mathrm{~m}]$ were chosen to be the constraints in current aerodynamic-thermal/structural optimization problems. Having in mind successively conducted V\&V routines regarding fin static structural experiment [47], these numerical results are assumed as trustable. 


\section{Definition of the Optimization Problems}

MDO problem of the missiles should be essentially defined as a multi-objective as well as a highly multi-point study. The present study observes two similar formulations of the optimization problem (ftsi_o and $\mathbf{f t s i}{ }^{*} \mathbf{o}$ case studies) which are resulted in significant difference between achieved results regarding objectives. This dually defined optimization problem represents a searching routine for the best possible aerodynamic shape of the fin structure. The only difference between these two studies is exclusion of the fin mass constraint within ftsi*_o optimization problem formulation. The ftsi_o optimization problem is defined with both the objective as well as with the constraint regarding fin mass as it was done in [47]. Both optimization formulations are described in detail in subsection 4.3 and formulated in 4.4. One more thing should be mentioned, $\mathbf{f t s i}{ }^{*} \_\mathbf{o}$ case study was conducted only for overall multi-point problem as the only relevant problem (observing all three Mach numbers). The ftsi_o case study was being concerned with all single- and multi-point problems with the purpose of comparison with the results published in the previous study (fsi_o case study) [47]. The aim was to depict in comparative form evolution and behavior of the fin geometries through each single-point and different combination of multi-points when thermal effects are and are not taken into consideration (Figs. 6-12).

\section{A. Objectives}

In both formulations (ftsi_o and $\mathbf{f t s i}{ }^{*} \_\mathbf{o}$ case studies) the objectives of the optimization process are to maximize lift-to-drag ratio (missile fitness) and to minimize mass of the fin structure.

\section{B. Design Variables and Material Properties}

The design variables represent geometrical dimensions of the fin structure. The design variables are presented in Table 1 with their initial values along with their lower and upper boundaries.

The material of the fin structure is Perunal 205-T6 [68], with density of $2780\left[\mathrm{~kg} / \mathrm{m}^{3}\right]$, Poisson's coefficient of 0.33, Young's modulus of 740 [GPa], ultimate tensile strength of 450 [MPa], yield strength of $300[\mathrm{MPa}$, coefficient of thermal expansion of $2.4 \cdot 10^{-5}\left[\mathrm{~K}^{-1}\right]$, thermal conductivity of $156[\mathrm{~W} / \mathrm{mK}]$ and specific heat of 963 $[\mathrm{J} / \mathrm{kgK}]$. 
Table 1 Range of design variables

\begin{tabular}{llcc}
\hline \hline Design variables & & Initial geometry & Lower and upper boundaries \\
\hline Fin span: $X_{1}$ & {$[\mathrm{~m}]$} & 0.500 & $0.350-0.500$ \\
Root chord length: $X_{2}$ & {$[\mathrm{~m}]$} & 0.715 & $0.7150-1.0725$ \\
Tip chord length: $X_{3}$ & {$[\mathrm{~m}]$} & 0.285 & $0.1425-0.4275$ \\
Angle between l.e. and $z$-axis: $X_{4}$ & {$\left[{ }^{\circ}\right]$} & 40.69 & $35-60$ \\
Tip thickness: $X_{5}$ & {$[\mathrm{~m}]$} & 0.0057 & $0.00285-0.00570$ \\
Aspect ratio: & {$[-]$} & 1 & - \\
\hline \hline
\end{tabular}

Numerical experimental points were generated by the design of experiments technique. For current multidisciplinary study, as a recommendation for total number of 5 design variables, 27 experimental points were created [56]. Each experimental point is defined by three exploitation regime points, thus representing multi-point problem, where each exploitation phase is numerically modeled as an aerothermoelastic analysis of the missile and its fin structure. For this kind of very robust numerical analysis around 80 hours were needed to generate these 27 numerical experimental points.

\section{Multi-Points and Constraints}

Observed multi-point conditions present critical exploitation phases in the boost regime (Fig. 4). They are described by three different exploitation Mach numbers achieved at different altitudes, with the angle of attack of $5^{\circ}$ and inertial and gravitational accelerations in appropriate directions. Critical exploitation phases are defined as:

$$
\begin{aligned}
& \alpha=5^{\circ}, \\
& M=1.4, H=5000[\mathrm{~m}], a_{z}=1.27\left[\mathrm{~m} / \mathrm{s}^{2}\right], a_{x}=22.42\left[\mathrm{~m} / \mathrm{s}^{2}\right], g=9.81\left[\mathrm{~m} / \mathrm{s}^{2}\right] \\
& M=2.3, H=10200[\mathrm{~m}], a_{z}=2.3\left[\mathrm{~m} / \mathrm{s}^{2}\right], a_{x}=36.11\left[\mathrm{~m} / \mathrm{s}^{2}\right], g=9.81\left[\mathrm{~m} / \mathrm{s}^{2}\right] \\
& M=4.0, H=17000[\mathrm{~m}], a_{z}=4.16\left[\mathrm{~m} / \mathrm{s}^{2}\right], a_{x}=58.17\left[\mathrm{~m} / \mathrm{s}^{2}\right], g=9.81\left[\mathrm{~m} / \mathrm{s}^{2}\right]
\end{aligned}
$$

The results of conducted aerothermoelastic analysis are shown in Table 2. These results represent thermally influenced aeroelastic responses for multi-point conditions of the ballistic missile and its fin with initial geometry. Conducted numerical aerothermoelastic calculations consume 18.5 GB RAM and need 60 minutes of execution time for each single point. 


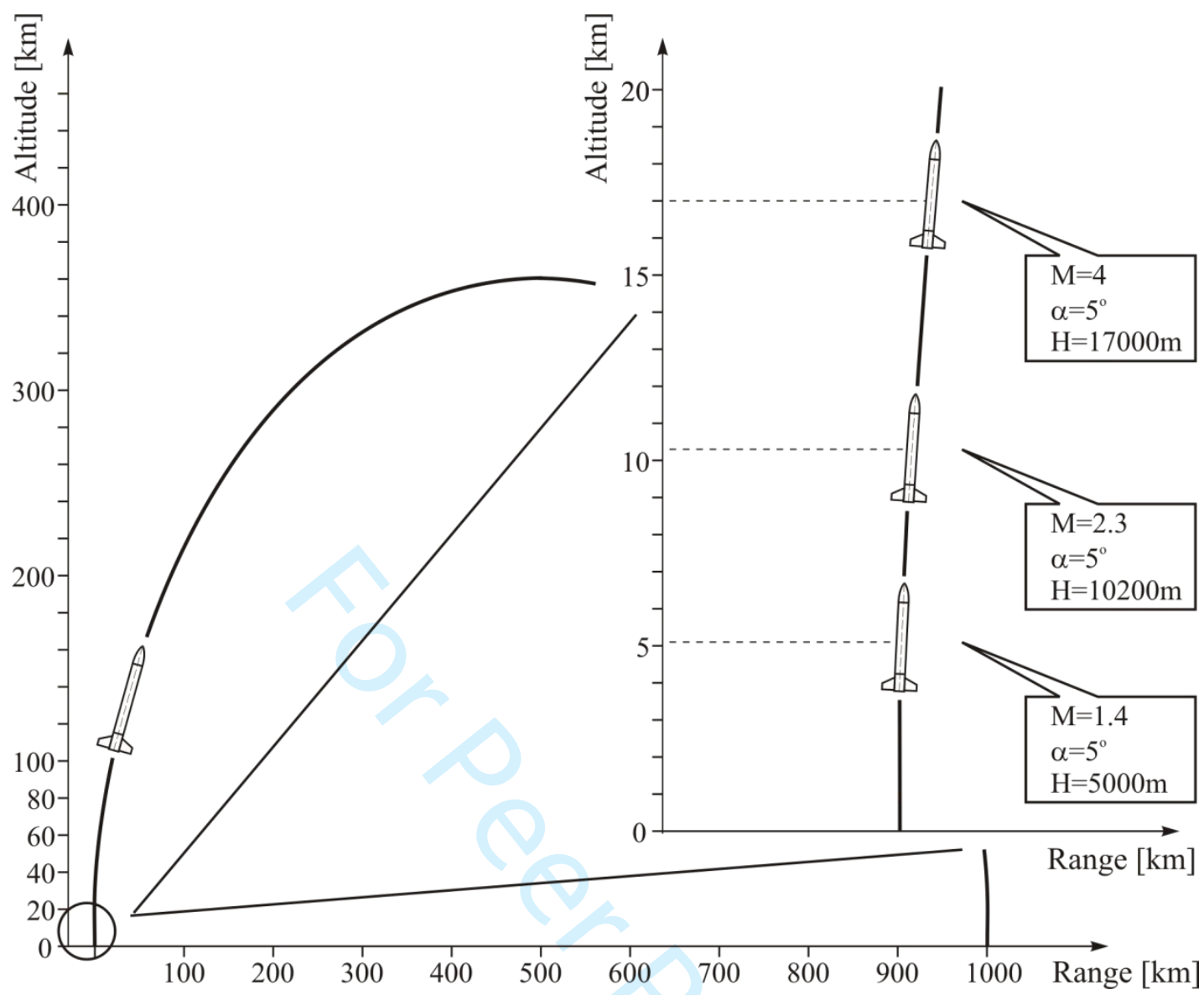

Fig. 4 Critical exploitation phases in boost regime [47] 
Table 2 Aerodynamic and structural responses for initial geometry

\begin{tabular}{|c|c|}
\hline Fin span: & $0.500[\mathrm{~m}]$ \\
\hline Root chord length: & $0.715[\mathrm{~m}]$ \\
\hline Tip chord length: & $0.285[\mathrm{~m}]$ \\
\hline Angle between l.e. and $z$-axis: & $40.69\left[^{\circ}\right]$ \\
\hline Tip thickness: & $0.0057[\mathrm{~m}]$ \\
\hline Fin mass: & $6.79[\mathrm{~kg}]$ \\
\hline Fin area: & $0.5025\left[\mathrm{~m}^{2}\right]$ \\
\hline$F l_{\text {fin }}(M=1.4)$ & $5753.9[\mathrm{~N}]$ \\
\hline$F \vec{d}_{f i n}(M=1.4)$ : & $683.72[\mathrm{~N}]$ \\
\hline$F l_{\text {fin }}(M=2.3)$ & $4520.5[\mathrm{~N}]$ \\
\hline$F d_{f i n}(M=2.3)$ : & $591.13[\mathrm{~N}]$ \\
\hline$F l_{\text {fin }}(M=4.0)$ & $2706.7[\mathrm{~N}]$ \\
\hline$F \vec{d}_{f i n}(M=4.0)$ : & $375.61[\mathrm{~N}]$ \\
\hline$f_{f i n}(M=1.4)$ & 8.416 \\
\hline$f_{\text {fin }}(M=2.3)$ & 7.647 \\
\hline$f_{\text {fin }}(M=4.0)$ & 7.206 \\
\hline Deflection on pos. $3(M=1.4)$ : & $0.02930[\mathrm{~m}]$ \\
\hline Deflection on pos. $7(M=1.4)$ : & $0.03294[\mathrm{~m}]$ \\
\hline Deflection on pos. $3(M=2.3)$ : & $0.02573[\mathrm{~m}]$ \\
\hline Deflection on pos. $7(M=2.3)$ : & $0.03052[\mathrm{~m}]$ \\
\hline Deflection on pos. $3(M=4.0)$ : & $0.02447[\mathrm{~m}]$ \\
\hline Deflection on pos. $7(M=4.0)$ : & $0.03014[\mathrm{~m}]$ \\
\hline c.p. $(M=1.4)$ : & $5.527[\mathrm{~m}]$ \\
\hline c.p. $(M=2.3)$ : & $4.736[\mathrm{~m}]$ \\
\hline c.p. $(M=4.0)$ : & $3.924[\mathrm{~m}]$ \\
\hline c.g.: & $3.70[\mathrm{~m}]$ \\
\hline$f_{\text {missile }}(M=1.4)$ : & 1.699 \\
\hline$f_{\text {missile }}(M=2.3)$ : & 1.482 \\
\hline$f_{\text {missile }}(M=4.0)$ : & 1.569 \\
\hline
\end{tabular}

In this optimization problem several constraints were defined. The first group of constrains force objectives to be more strict: missile fitness $\left(f_{\text {missile }}\right)$ has to be grater or equal then initial, while the fin mass $\left(m_{f i n}\right)$ within ftsi_o optimization formulation has to be lesser or equal then initial. Within $\mathbf{f t s i}^{*} \mathbf{o}_{-}$formulation this constraint is excluded which affects cost increase of the theoretical fin production.

The second group of constraints enforce maximum deflections of the fin tips to be lesser or equal then $u_{3}=$ $0.02058[\mathrm{~m}]$ and $u_{7}=0.02370[\mathrm{~m}]$, difference between vertical deflections at positions 7 and 3 to be greater than zero $\left(\Delta_{1.4}, \Delta_{2.3}, \Delta_{4.0}\right)$, thus preventing possible occurrence of the divergence, and finally, the missile centre of pressure (c.p.) for $M=4.0$ to be greater or equal then 3.8 [m]. This constraint forces c.p. to be behind the missile centre of gravity (c.g.) which ensures stability of the missile [69]. As a well known aerodynamic behavior, this single-point regime provides the shortest distance between these two coordinates. As a last constraint, the fin area ( $S$ fin) is forced to be greater or equal to the initial. 


\section{Optimization Problem Formulation and Settings}

First optimization problem (ftsi_o case study) is formulated as:

$$
\max f_{\text {missile }_{I N I}}^{1.4}(X), \max f_{\text {missile }_{I N I}}^{2.3}(X), \max f_{\text {missile }_{I N I}}^{4.0}(X), \min m_{f i n}(X),
$$

subject to:

$$
\begin{aligned}
& f_{\text {missile }}^{1.4}(X) \geq f_{\text {missile } I N I}^{1.4}, f_{\text {missile }}^{2.3}(X) \geq f_{\text {missile }_{I N I}^{2.3}}, f_{\text {missile }}^{4.0}(X) \geq f_{\text {missile }_{\text {INI }}}^{4.0}, m_{\text {fin }}(X) \leq m_{\text {fin }} \text { INI } \text {, } \\
& S_{f i n}(X) \geq S_{f_{\text {in }} I N I}, \text { c.p. }(X) \geq 3.8[m], u_{3}(X) \leq 0.02058[m], u_{7}(X) \leq 0.02370[m] \text {, } \\
& \Delta_{1.4}(X)>0[m], \Delta_{2.3}(X)>0[m], \Delta_{4.0}(X)>0[m], \\
& X=X_{i}, \quad i=1, \ldots, 5 \text {. }
\end{aligned}
$$

Second optimization problem (ftsi*_o case study), as mentioned earlier, is formulated in the same way but with exclusion of the fin mass constraint: $m_{f i n}(X) \leq m_{f i n}$ INI

Configuration for all optimization points was set up in the same way [47]. Non-iterative screening algorithm was selected for the purpose of initial population sampling. As a maximum allowable value, 10000 was set to be the number of samples within initial population. The mutation was set to be 0.01 , the crossover was set to be 0.98 , the stop criterion was defined by 50 iterations/generations and the convergence criterion was predefined as $70 \%$ of maximum allowable Pareto percentage (MAPP). For overall multi-point optimization problem MAPP criterions for both optimization formulations are presented on convergence diagram (Fig. 5). In both case studies predefined convergence criterion value was reached. In ftsi*_o case study convergence criterion was reached when the 25 th iteration/generation (around 3h was needed) was calculated while in ftsi_o case study formulation convergence criterion was reached when the 34th iteration/generation (around 3h25min was needed) was calculated. 


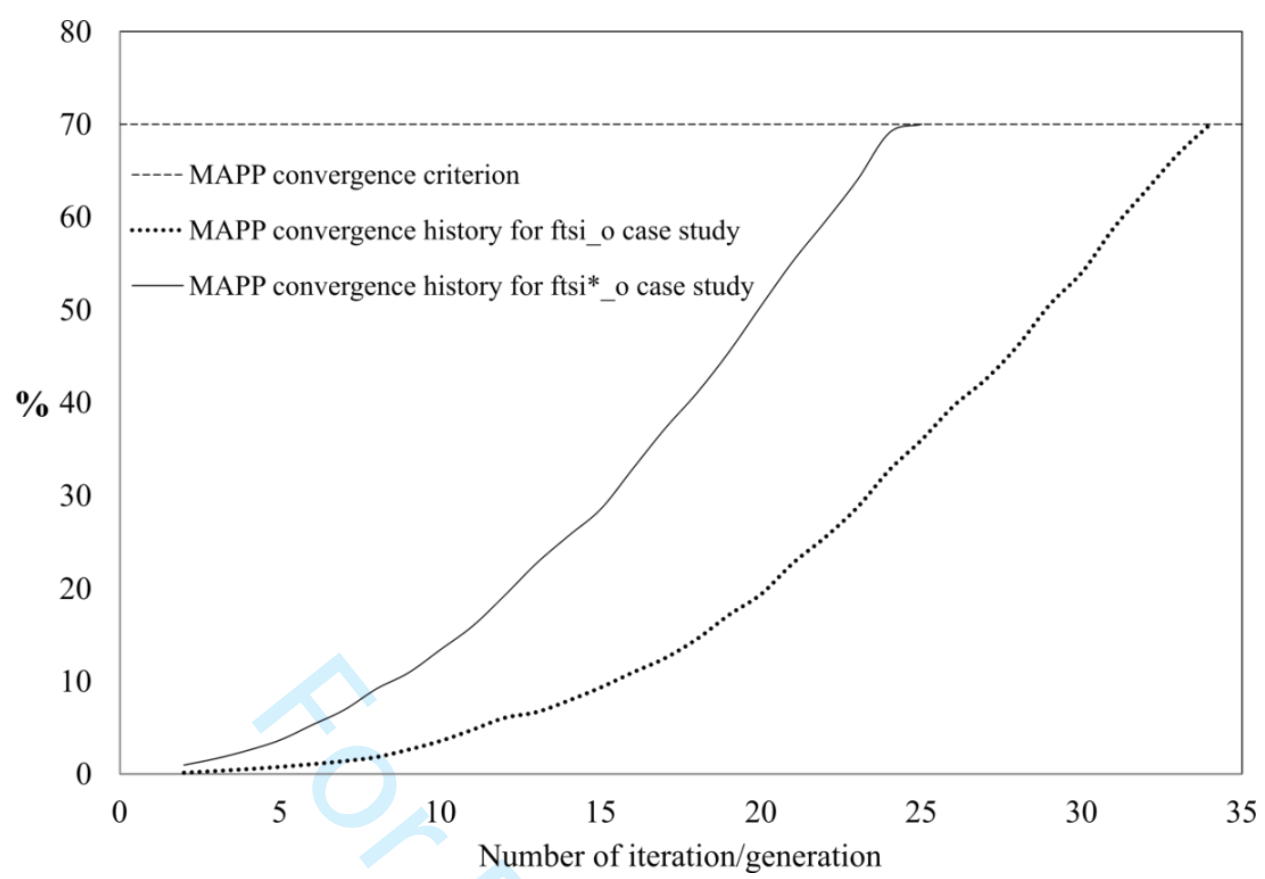

Fig. 5 MAPP convergence criterion and convergence histories for ftsi_o and ftsi*_o case studies with respect to number of iteration/generation for the overall multi-point optimization problem

\section{Results and Discussion}

\section{A. Surrogate Model Prediction Verification}

The outcome of the surrogate model verification is presented in Table 3 . The table only presents parameters which were included in optimization formulations as objectives or constraints. As it can be seen, those differences are well under $10 \%$, except in few cases where the differences are $12.01 \%, 12.37 \%$ and $13.98 \%$. These differences refer to deflection at location 7 for overall multi-point problem for ftsi“__o case study at $M=1.4$ and to deflections at location 3 and 7 for multi-point problem defined by $M=2.3$ and $M=4.0$ at $M=4.0$, respectively. However in all of these cases the deflections are inside the predefined constraints. These differences are possibly caused by the number of only 27 generated experimental points, which was predefined by standard template type selection as one of the central composite design properties [56]. Generated differences could be minimized with enhanced template type selection, which requires 53 experimental points to be generated or with the selection of some other more complex surrogate modeling technique thus ensuring better fitting of aerodynamic and structural responses. Also, selection of the other types of design of experiments could result in percentage differences reduction between surrogate-based predicted results and numerical results. 
Table 3 Percentage differences between surrogate-based predicted results and numerical results

\begin{tabular}{|c|c|c|c|c|c|c|c|}
\hline Output parameters & $M=1.4$ & $M=2.3$ & $M=4.0$ & $\begin{array}{l}M=1.4 \\
M=2.3\end{array}$ & $\begin{array}{l}M=1.4 \\
M=4.0\end{array}$ & $\begin{array}{l}M=2.3 \\
M=4.0\end{array}$ & $\begin{aligned} M & =1.4 \\
M & =2.3 \\
M & =4.0\end{aligned}$ \\
\hline Fin mass: & 0.00 & 0.00 & 0.31 & 0.15 & 0.15 & 0.15 & $\begin{array}{c}0.00 \\
0.00^{*}\end{array}$ \\
\hline Fin area: & 0.00 & 0.00 & 0.26 & 0.00 & 0.18 & 0.00 & $\begin{array}{c}0.00 \\
0.03 *\end{array}$ \\
\hline Def. on pos. $3(M=1.4)$ : & 0.13 & & & 1.87 & 0.08 & & $\begin{array}{c}3.09 \\
4.76^{*}\end{array}$ \\
\hline Def. on pos. $7(M=1.4)$ : & 0.68 & & & 0.19 & 5.05 & & $\begin{array}{c}4.85 \\
12.01 *\end{array}$ \\
\hline Def. on pos. $3(M=2.3)$ : & & 1.40 & & 3.33 & & 1.95 & $\begin{array}{l}1.03 \\
6.18^{*}\end{array}$ \\
\hline Def. on pos. $7(M=2.3)$ : & & 7.12 & & 4.15 & & 2.53 & $\begin{array}{c}3.63 \\
7.37^{*}\end{array}$ \\
\hline Def. on pos. $3(M=4.0)$ : & & & 7.88 & & 8.09 & 12.37 & $\begin{array}{c}3.36 \\
2.24^{*}\end{array}$ \\
\hline Def. on pos. $7(M=4.0)$ : & & & 4.80 & & 6.61 & 13.98 & $\begin{array}{c}4.80 \\
7.64^{*}\end{array}$ \\
\hline c.p. $(M=4.0)$ : & & & 0.50 & & 0.25 & 0.25 & $\begin{array}{c}0.25 \\
0.48^{*}\end{array}$ \\
\hline$f_{\text {missile }}(M=1.4)$ : & 0.81 & & & 0.34 & 0.45 & & $\begin{array}{c}0.80 \\
2.19^{*}\end{array}$ \\
\hline$f_{\text {missile }}(M=2.3)$ : & & 0.73 & & 0.89 & & 1.38 & $\begin{array}{c}0.70 \\
1.05^{*}\end{array}$ \\
\hline$f_{\text {missile }}(M=4.0)$ : & & & 1.42 & & 0.00 & 0.93 & $\begin{array}{c}0.60 \\
0.17 *\end{array}$ \\
\hline
\end{tabular}

\section{B. Optimization Results}

The obtained results are compared with the results from the previous study, which was accomplished without thermal effects (fsi_i and fsi_o case studies). Optimized fin geometries for ftsi_o case study (dotted line) and for previously conducted fsi_o case study (solid line) for different single- and multi-points relative to initial fin geometry (dashed line) are shown in Fig. 6-12. For overall multi-point problem Fig. 13 presents comparative view between all optimized fin geometries relative to initial one where the optimized fin geometry for $\mathbf{f t s i}{ }^{*} \mathbf{o}$ case study is symbolized by dash-dot line type. As it can be seen all optimized geometries have reduced fin span, increased root and tip chord and angle between leading edge (l.e.) and z-axis. The thickness of the airfoil at the fin tip is also reduced for all optimized geometries. Further, as in previous study, it can be observed that geometries in Fig. 6, 9, 10,12 and 13 are very similar. In all of these cases $M=1.4$ exploitation point is present. This flight condition generates the greatest aerodynamic loads (Table 4). Observing affected deflections for initial geometries and 
corresponding differences between them (Table 4) it is easy to conclude that this flight condition generates aerodynamic loads whose contribution dominates over generated thermal loads at any of the exploitation Mach number and consequently presents the most dominant flight condition regarding geometry.

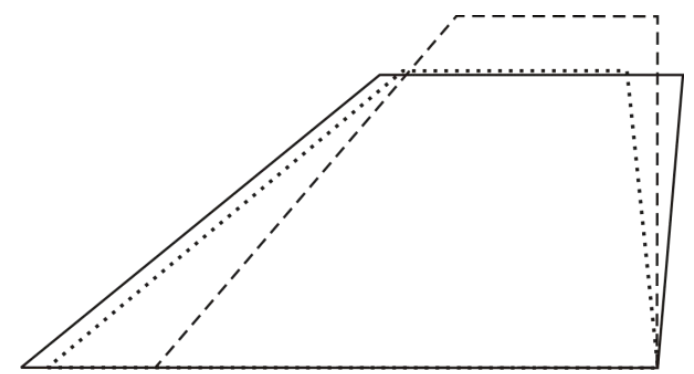

Fig. 6 Optimized geometries for $M=1.4, H=5000[\mathrm{~m}], \alpha=5^{\circ}$

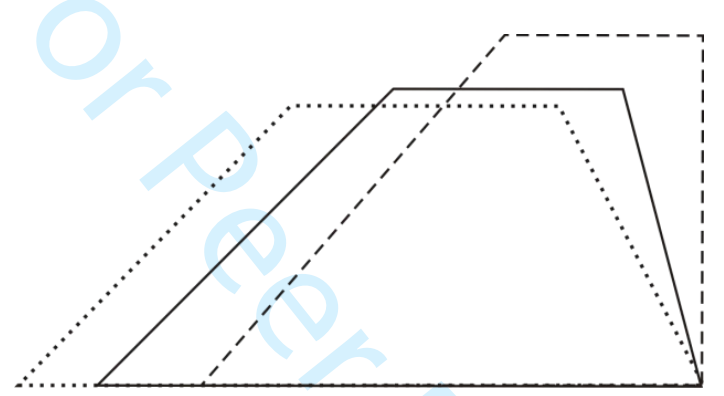

Fig. 7 Optimized geometries for $M=2.3, H=10200[\mathrm{~m}], \alpha=5^{\circ}$

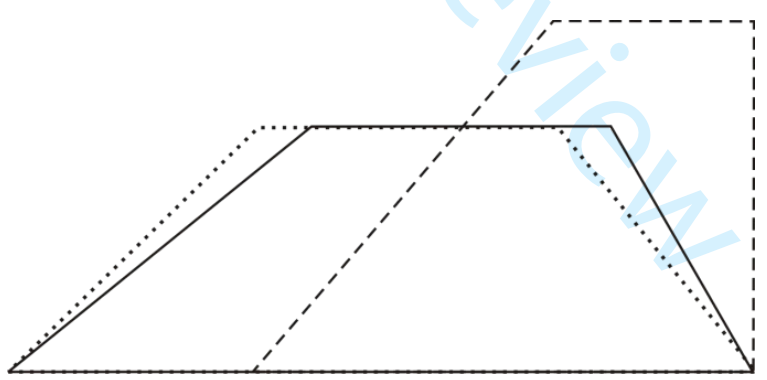

Fig. 8 Optimized geometries for $M=4.0, H=17000[\mathrm{~m}], \alpha=5^{\circ}$

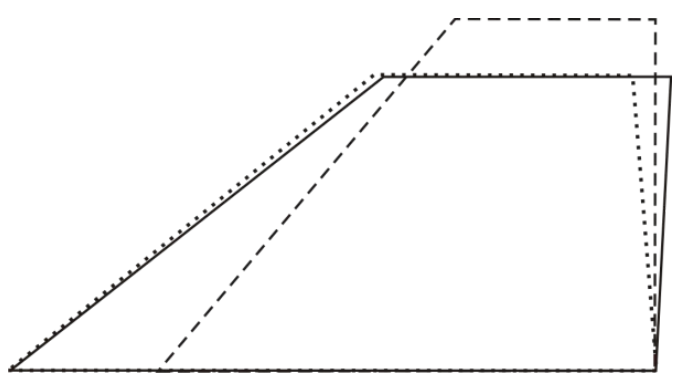

Fig. 9 Optimized geometries for $M=1.4, H=5000[\mathrm{~m}], M=2.3, H=10200[\mathrm{~m}], \alpha=5^{\circ}$ 


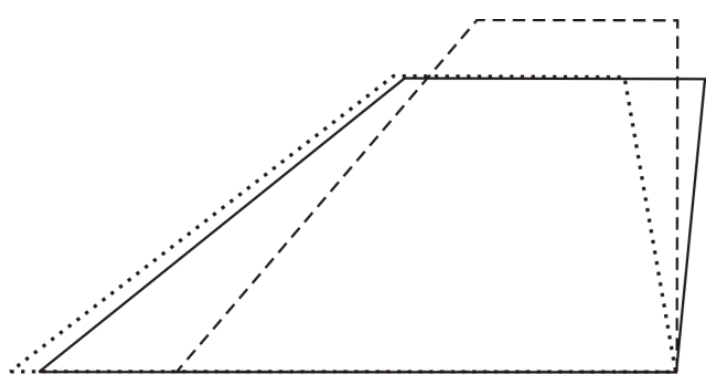

Fig. 10 Optimized geometries for $M=1.4, H=5000[\mathrm{~m}], M=4.0, H=17000[\mathrm{~m}], \alpha=5^{\circ}$

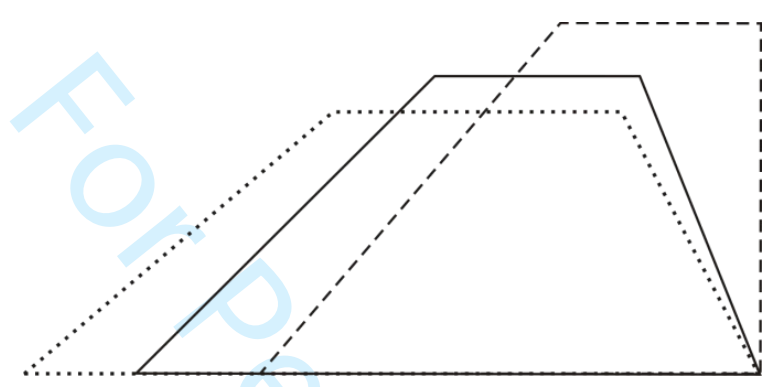

Fig. 11 Optimized geometries for $M=2.3, H=10200[\mathrm{~m}], M=4.0, H=17000[\mathrm{~m}], \alpha=5^{\circ}$

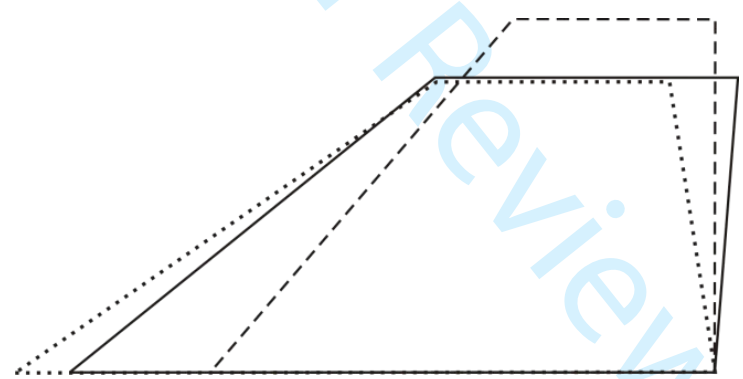

Fig. 12 Optimized geometries for $M=1.4, H=5000[\mathrm{~m}], M=2.3, H=10200[\mathrm{~m}], M=4.0, H=17000[\mathrm{~m}], \alpha$ $=5^{\circ}$

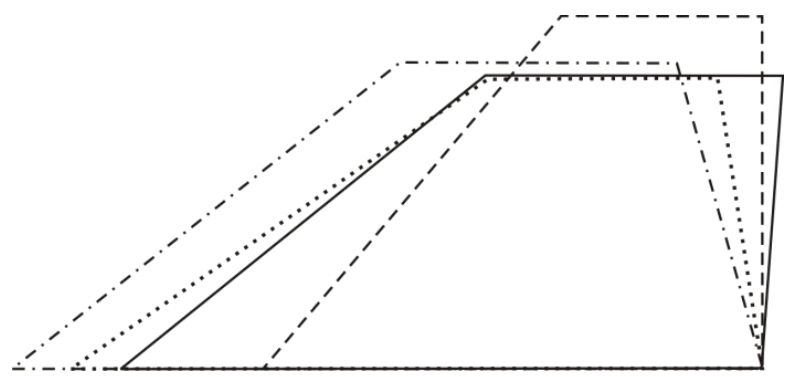

Fig. 13 Optimized geometries for $M=1.4, H=5000[\mathrm{~m}], M=\mathbf{2 . 3}, H=10200[\mathrm{~m}], M=4.0, H=17000[\mathrm{~m}], \alpha$ $=5^{\circ}$ 
All generated surrogate-based solutions for both case studies as a function of Mach numbers for overall multipoint optimization problem are shown in Fig. 14 and Fig. 15. These results are presented relative to aerodynamic efficiency and fin mass objective functions, where correspondence between them can be observed. The Paretooptimal solutions can be spotted as solutions spreading on the upper boundaries of the generated feasible regions thus representing Pareto-optimal fronts. The figures show 9991 feasible candidates, generated by ftsi_o formulation (Fig. 14), and 9762 feasible candidates, generated by ftsi*_o formulation (Fig. 15).

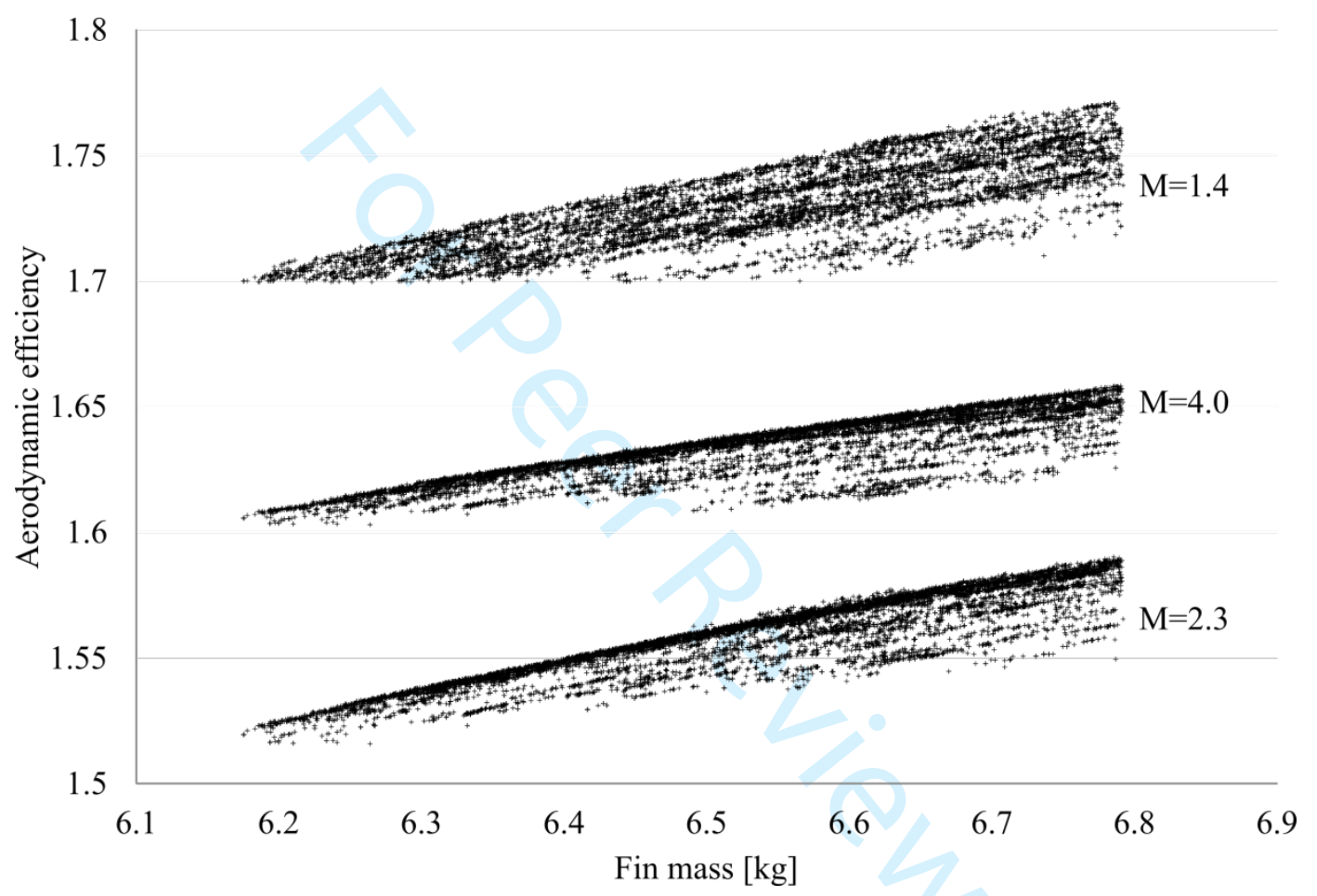

Fig. 14 Generated feasible solutions with Pareto-optimal solutions for ftsi_o case study as a function of Mach numbers for overall multi-point optimization problem 


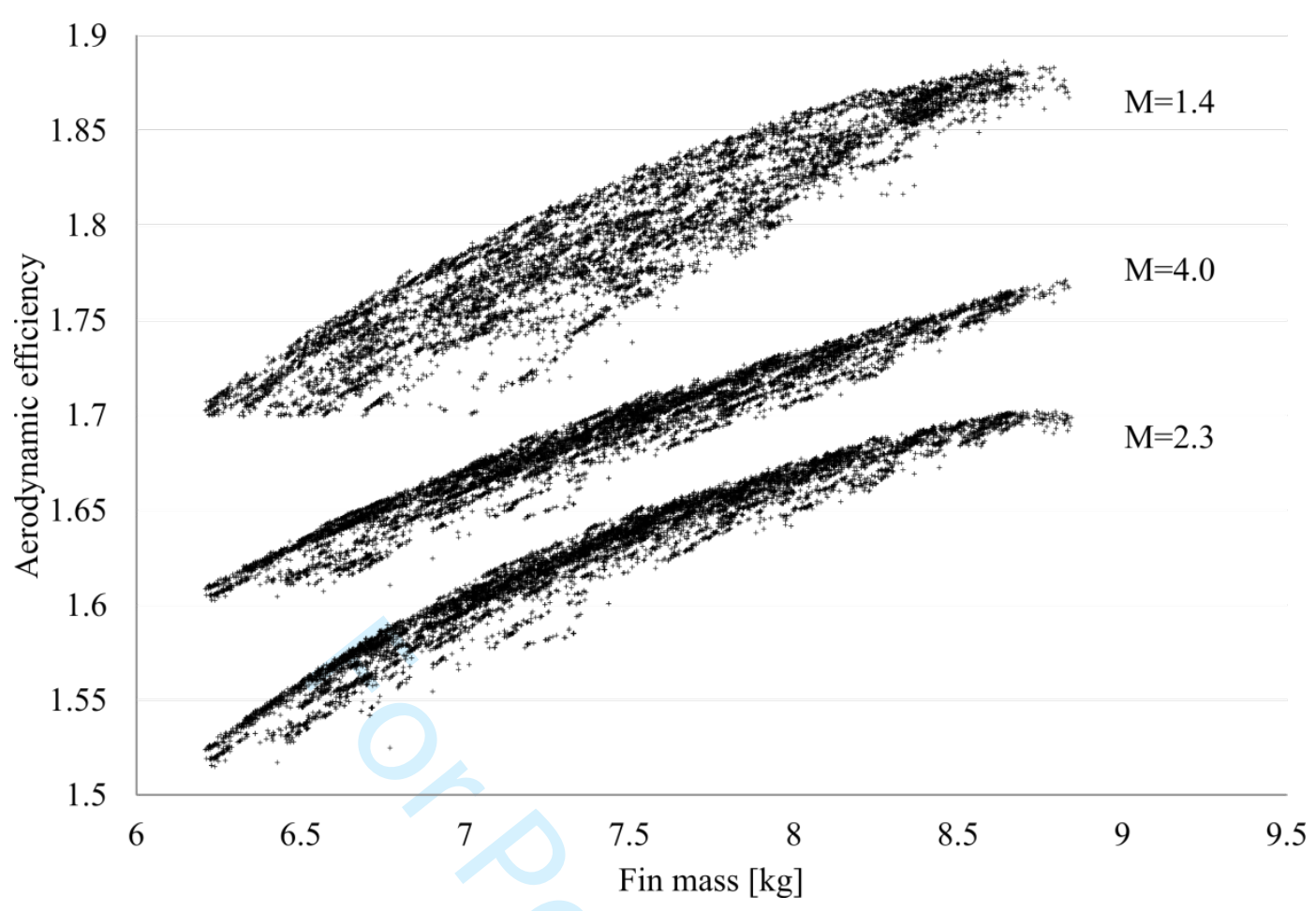

Fig. 15 Generated feasible solutions with Pareto-optimal solutions for ftsi*_o case study as a function of Mach numbers for overall multi-point optimization problem

The ballistic missile model with all optimized fin shapes relative to initial fin shape is presented in Fig. 16.

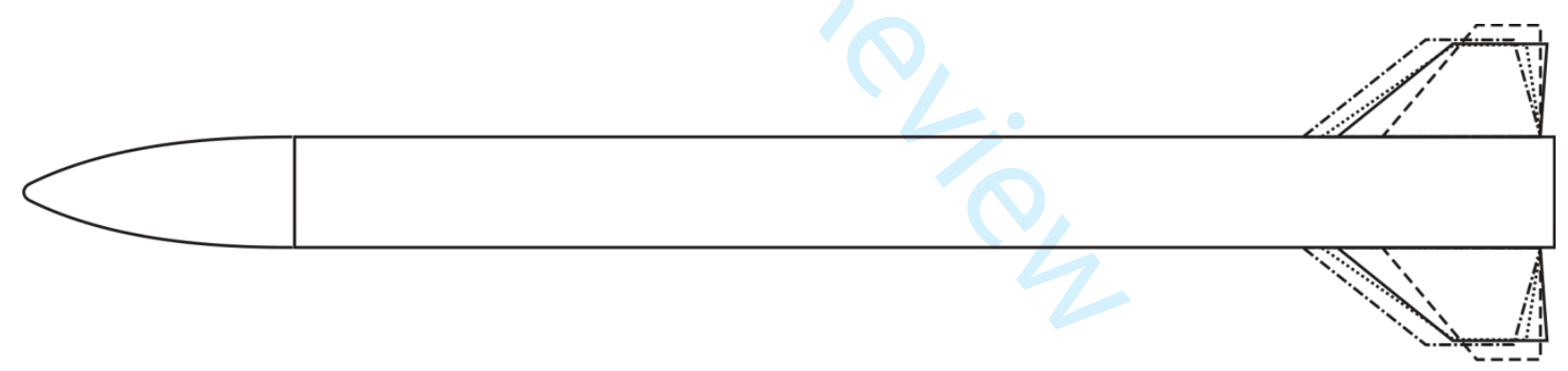

Fig. 16 Ballistic missile model with initial (dashed line), fsi_o (solid line), ftsi_o (dotted line) and ftsi*_o (dash-dot line) optimized fin shapes for overall multi-point study

In a comparative form Table 4 presents general contributions (-/+ improvements in percent) of aerodynamic and structural responses of the missile model for overall multi-point analyses. Also, Table 4 presents general contributions for design variables of the missile fin. The most significant results from the table are commented in the following text.

The optimization results obtained for overall multi-point exploitation problem, defined by all Mach numbers each achieved at different altitudes, are assumed as the most relevant results. The best possible results, relative to 
aerodynamic and structural responses for initial geometry (ftsi_i), were obtained for $\mathbf{f t s i}{ }^{*} \_$o case study, where missile aerodynamic efficiency was upgraded by $12.83 \%$ at $M=1.4,15.99 \%$ at $M=2.3$ and $13.13 \%$ at $M=4.0$ while missile aerodynamic efficiency for ftsi_o case study was upgraded by $2.88 \%, 6.41 \%$ and $5.93 \%$, respectively.

Exclusion of the fin mass constraint within $\mathbf{f t s i}^{*}{ }_{-} \mathbf{o}$ optimization formulation, which scarifies the cost of the theoretical fin production due to needed amount of the Perunal 205-T6, leading to significant improvement of the aerodynamic efficiency. The fin mass was increased from initial $6.79[\mathrm{~kg}]$ to optimized $8.93[\mathrm{~kg}]$, i.e. by $31.52 \%$. This increase appears high regarding fin mass and this fact needs ,production cost/fitness improvement” evaluation study to be conducted and compromise should be established, but these two are something with which this paper is not concerned with. Also, it is useful to emphasize that value of $8.93[\mathrm{~kg}]$ is les then maximal possible value of $10.48[\mathrm{~kg}]$ extracted from $\min / \max$ search study. Observing whole missile with its minimal real mass of approximately $5000[\mathrm{~kg}]$ for this SRBM type, calculated percentage increase when the mass constraint is excluded is $0.17 \%$ and practically leads to conclusion that this increase could be estimated as negligible. The outcome of this observation represents justification for exclusion of this constraint in $\mathbf{f t s i { } ^ { * }}{ }_{-} \mathbf{o}$ case study. Furthermore, comparison of the results between two formulations of the optimization problem showed that there is an increase in aerodynamic efficiency of missile (ftsi*_o vs. ftsi_o) for $9.67 \%, 9.00 \%$ and $6.80 \%$, at each Mach number, respectively. So, it can be concluded that fin mass constraint exclusion can be assumed as more than justified.

The thermally influenced structural responses are best observed through increased deflections of the missile fin for initial geometries (ftsi_i vs. fsi_i). It can be seen that at $M=1.4$ increases at positions 3 and 7 are $6.78 \%$ and $10.09 \%$, at $M=2.3$ they are $28.39 \%$ and $35.40 \%$ and at $M=4.0$ they are $107.72 \%$ and $124.59 \%$. Also, increments of thermally induced deflections for initial geometries can be represented as a difference between deflections derived from ftsi_i numerical analysis and fsi_i numerical analysis. It is obvious that these percentage increases or increments are the result of the aerodynamic heating which is here taken into consideration. Temperature distribution for each exploitation Mach number on lower and upper fin surface of initial geometry is presented in Figs. 17,18 and 19. The temperature domains are between $250[\mathrm{~K}]$ and $330[\mathrm{~K}]\left(-23.15\left[{ }^{\circ} \mathrm{C}\right]\right.$ and $\left.56.85\left[{ }^{\circ} \mathrm{C}\right]\right)$ at $M=$ 1.4, between $240[\mathrm{~K}]$ and $370[\mathrm{~K}]\left(-33.15\left[{ }^{\circ} \mathrm{C}\right]\right.$ and $\left.96.85\left[{ }^{\circ} \mathrm{C}\right]\right)$ at $M=2.3$ and between $400[\mathrm{~K}]$ and $750[\mathrm{~K}]$ (126.85 $\left[{ }^{\circ} \mathrm{C}\right]$ and $\left.476.85\left[{ }^{\circ} \mathrm{C}\right]\right)$ at $M=4.0$. As it can be seen (Fig. 19), the region of the upper fin surface where the maximal temperature was occurred is small enough and could be assumed as negligible. This appearance could be dedicated to surface discretization. 


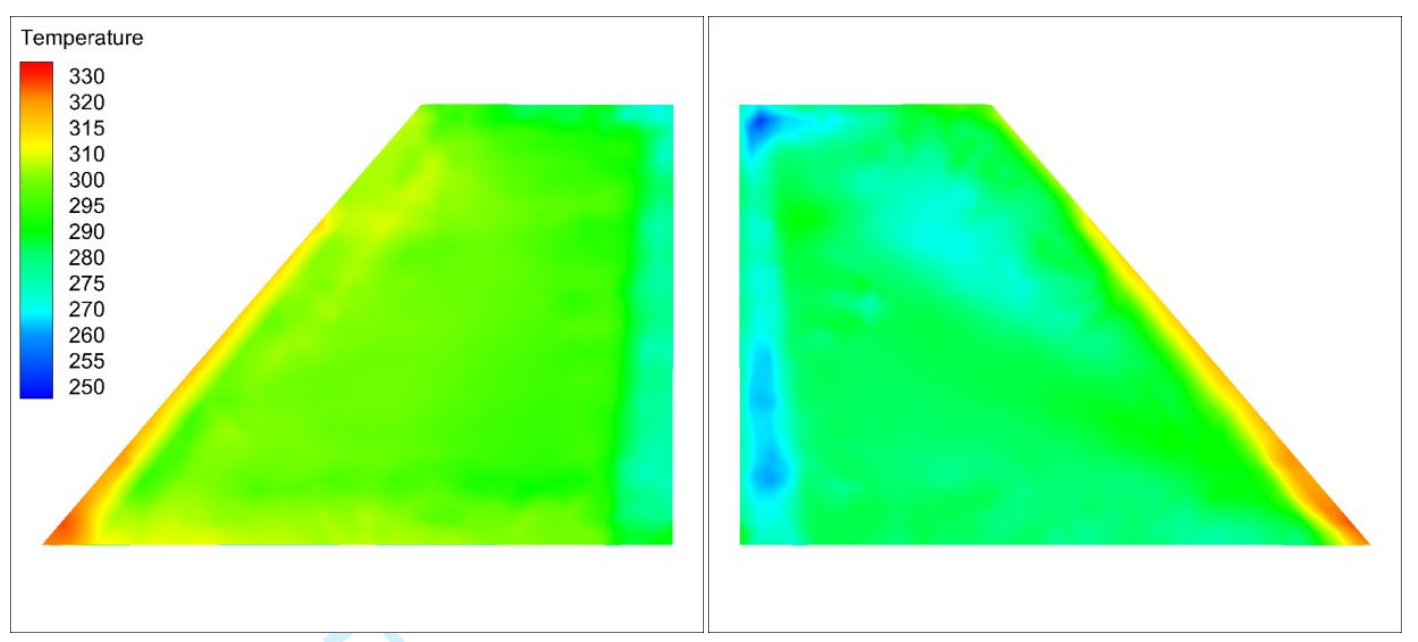

(a)

(b)

Fig. 17 Temperature distribution at $M=1.4$ on lower (a) and upper (b) fin surface of initial geometry

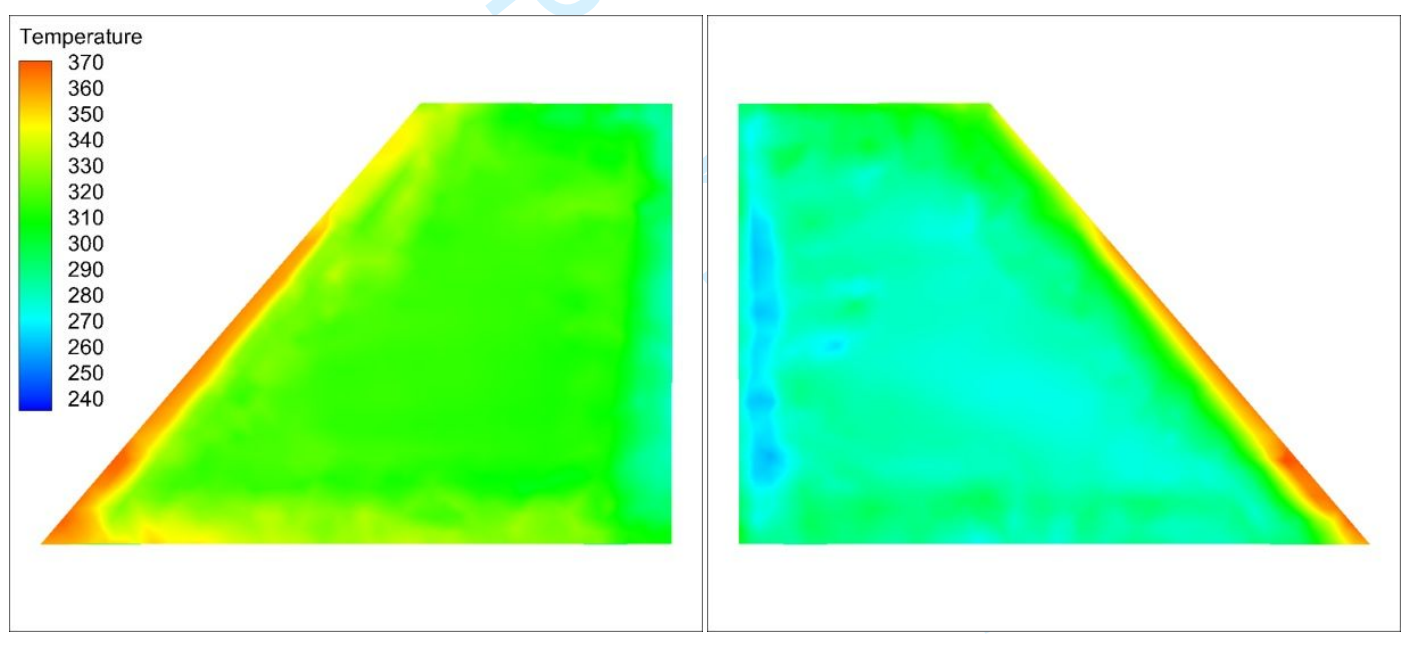

(a)

(b)

Fig. 18 Temperature distribution at $M=2.3$ on lower (a) and upper (b) fin surface of initial geometry 


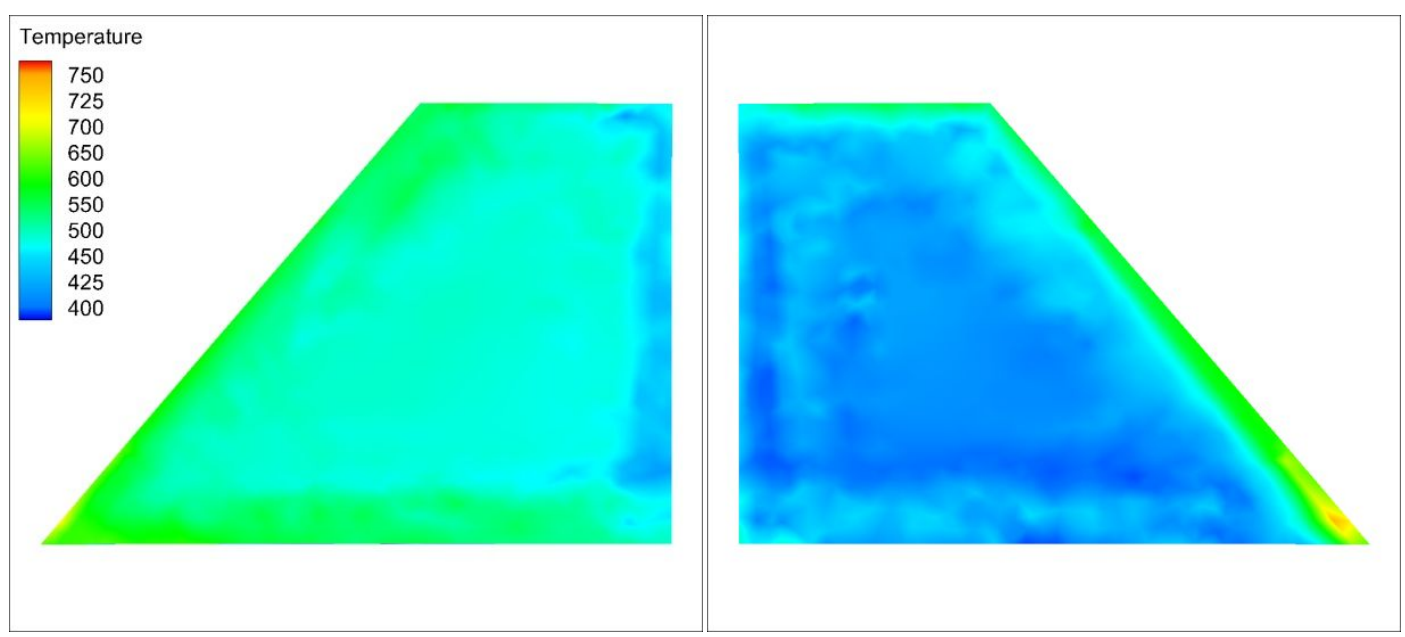

(a)

(b)

Fig. 19 Temperature distribution at $M=4.0$ on lower (a) and upper (b) fin surface of initial geometry

Temperature distribution for each exploitation Mach number on lower and upper fin surface of optimized geometry for ftsi*_o case study is presented in Figs. 20, 21 and 22. The temperature domains are between 265 [K] and $325[\mathrm{~K}]\left(-8.15\left[{ }^{\circ} \mathrm{C}\right]\right.$ and $\left.51.85\left[{ }^{\circ} \mathrm{C}\right]\right)$ at $M=1.4$, between $240[\mathrm{~K}]$ and $370[\mathrm{~K}]\left(-33.15\left[{ }^{\circ} \mathrm{C}\right]\right.$ and $\left.96.85\left[{ }^{\circ} \mathrm{C}\right]\right)$ at $M$ $=2.3$ and between $375[\mathrm{~K}]$ and $750[\mathrm{~K}]\left(101.85\left[{ }^{\circ} \mathrm{C}\right]\right.$ and $\left.476.85\left[{ }^{\circ} \mathrm{C}\right]\right)$ at $M=4.0$. As it can be seen (Fig. 22), the region of the upper fin surface where the maximal temperature was occurred is small enough, so the same conclusions could be stated as it was already done for the initial geometry for the same Mach number (Fig. 19). Temperature domains for ftsi_o case study are very similar with presented temperature domains for $\mathbf{f t s i}{ }_{-}^{*} \mathbf{o}$ case study. As it can be seen, these temperature domains for optimal geometries slightly differ from temperature domains for initial geometry. Also, it should be mentioned that the fin structure could be assumed as safe regarding melting point of the Perunal 205-T6 which is around $923.15[\mathrm{~K}]$ or $650\left[{ }^{\circ} \mathrm{C}\right]$. 


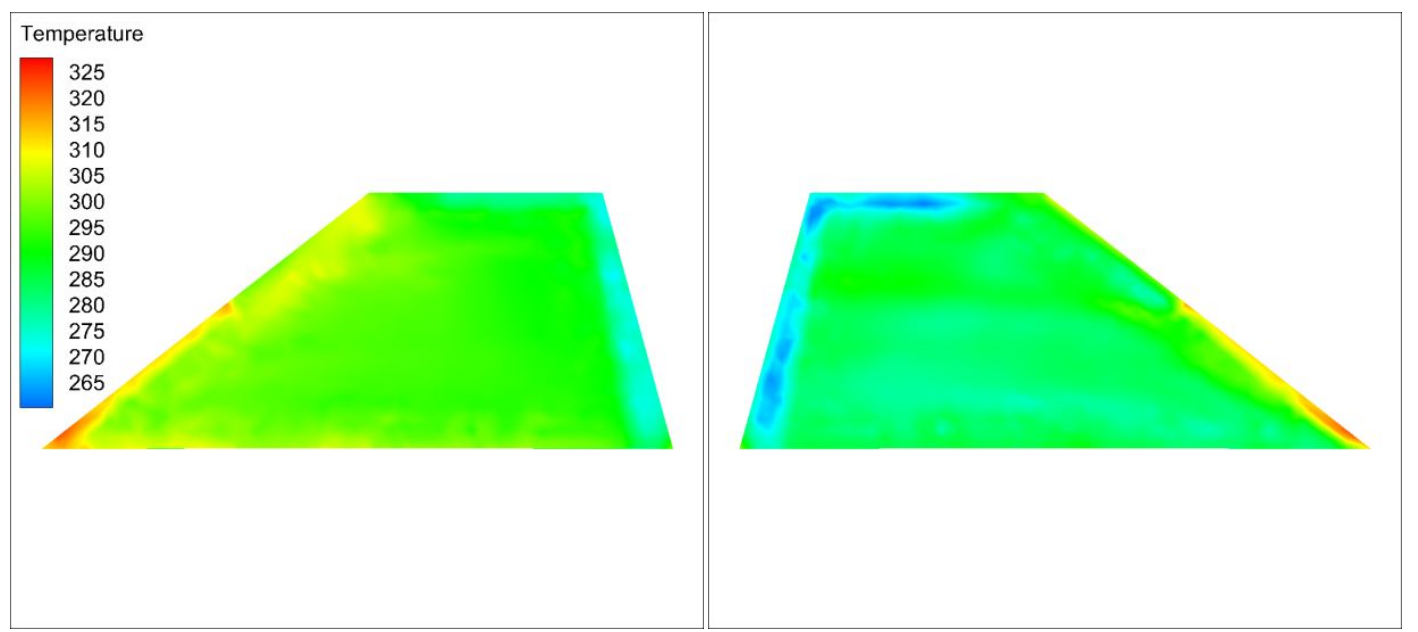

(a) (b)

Fig. 20 Temperature distribution at $M=1.4$ on lower (a) and upper (b) fin surface of optimized geometry for ftsi*_o case study

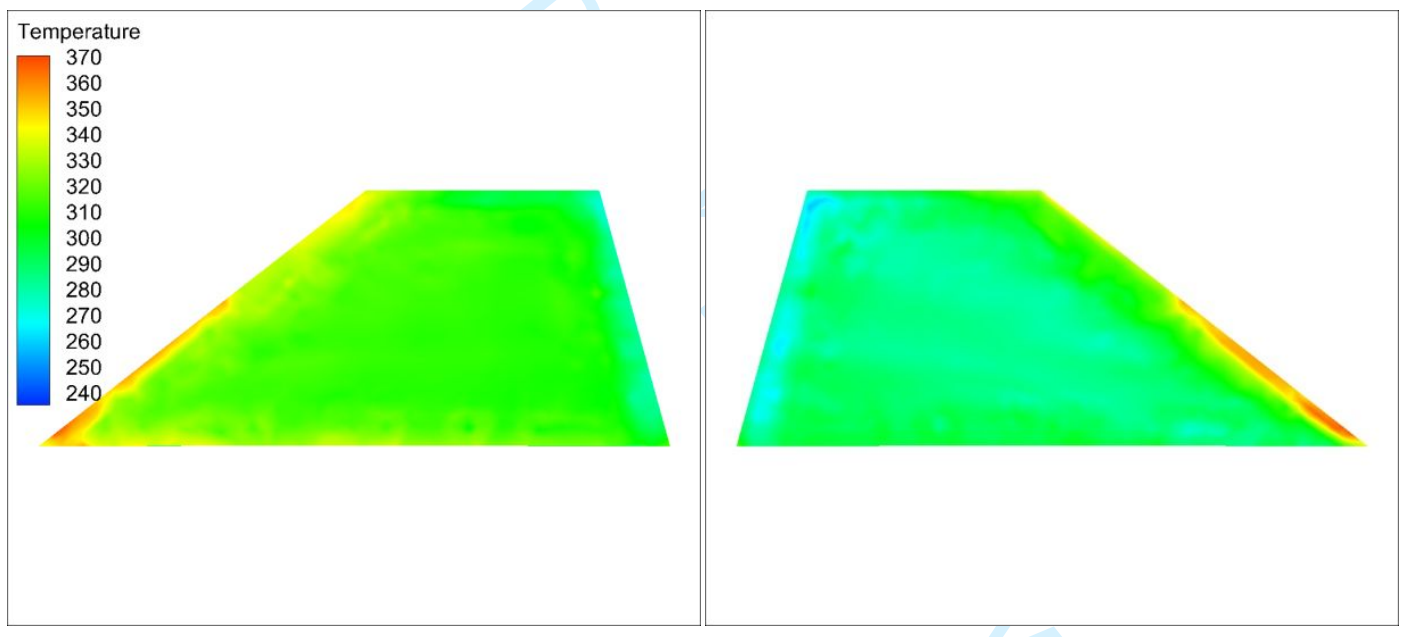

(a)

(b)

Fig. 21 Temperature distribution at $M=2.3$ on lower (a) and upper (b) fin surface of optimized geometry for ftsi*_o case study 


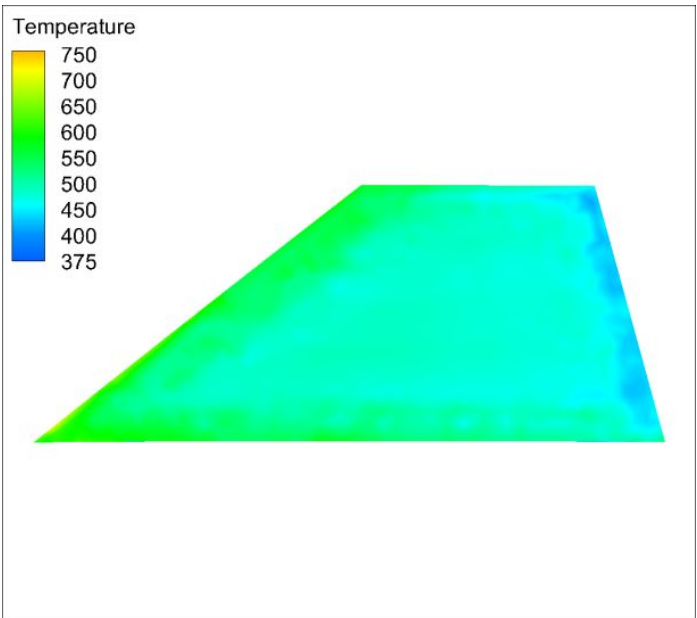

(a)

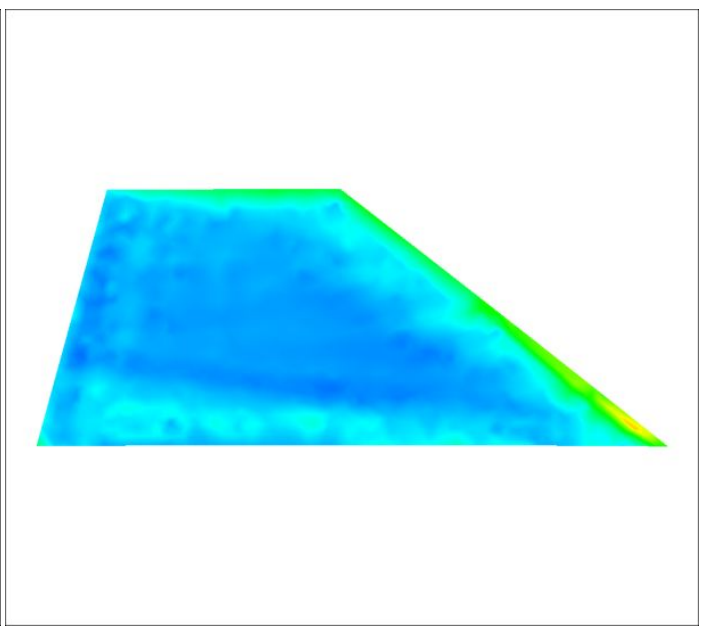

(b)

Fig. 22 Temperature distribution at $M=4.0$ on lower (a) and upper (b) fin surface of optimized geometry for ftsi*_o case study

Thermal influences caused degradation of aerodynamic efficiency of initial missile configuration (ftsi_i vs. fsi_i) by $2.36 \%$ at $M=1.4,1.20 \%$ at $M=2.3$ and $1.94 \%$ at $M=4.0$. As expected thermally influenced structural responses also caused degradation of optimized aerodynamic efficiency of missile (ftsi_o vs. fsi_o) by $1.69 \%$ at $M=1.4$, $0.57 \%$ at $M=2.3$ and $1.71 \%$ at $M=4.0$. This degradation is relatively small, though it actually means that the maximal possible range is shortened by $40[\mathrm{~km}]$. This can be assumed as a crucial reason why the second formulation of optimization was studied.

For both ftsi_o and $\mathbf{f t s i}{ }^{*} \_$o case studies, as it can be seen in Table 4, the difference between vertical deflections at positions 7 and 3 at $M=1.4$ does not satisfy the imposed constraint which has to be greater than zero. Furthermore, this behavior is intensified with the presence of thermal effects caused by aerodynamic heating. This structural behavior is naturally explained by the fact that transonic flow effects are still present for these two optimized fin shapes which can be easily confirmed by additionally conducted comparisons between transonic and supersonic simulated results for optimized fin shapes at the same altitude. This structural behavior suggests that more robust tri-sonic multi-point optimization study has to be conducted where probably narrow ranges of some design variables have to be defined.

Special contribution regarding achieved ranges was attained. Well-known Bregeut equation [47] approximates and describes range of missile as directly proportional to the fitness: $R \sim(L / D)$. If in Bregeut equation all variables are coarsely assumed to be constant except the term $(L / D)$, the overall range contribution could be approximately 
2

3

4

5

6

7

8

9

10

11

12

13

14

15

16

17

18

19

20

21

22

23

24

25

26

27

28

29

30

31

32

33

34

35

36

37

38

39

40

41

42

43

44

45

46

47

48

49

50

51

52

53

54

55

56

57

58

59

60

expressed as a sum of achieved fitness increase per each Mach number. Having in mind this coarse approximation, Fig. 23 depicts a schematic presentation of the achieved ranges for all optimization case studies relative to maximal possible range for the initial SRBM geometry, which is theoretically defined to be up to 1000 [km] for this type of ballistic missile.

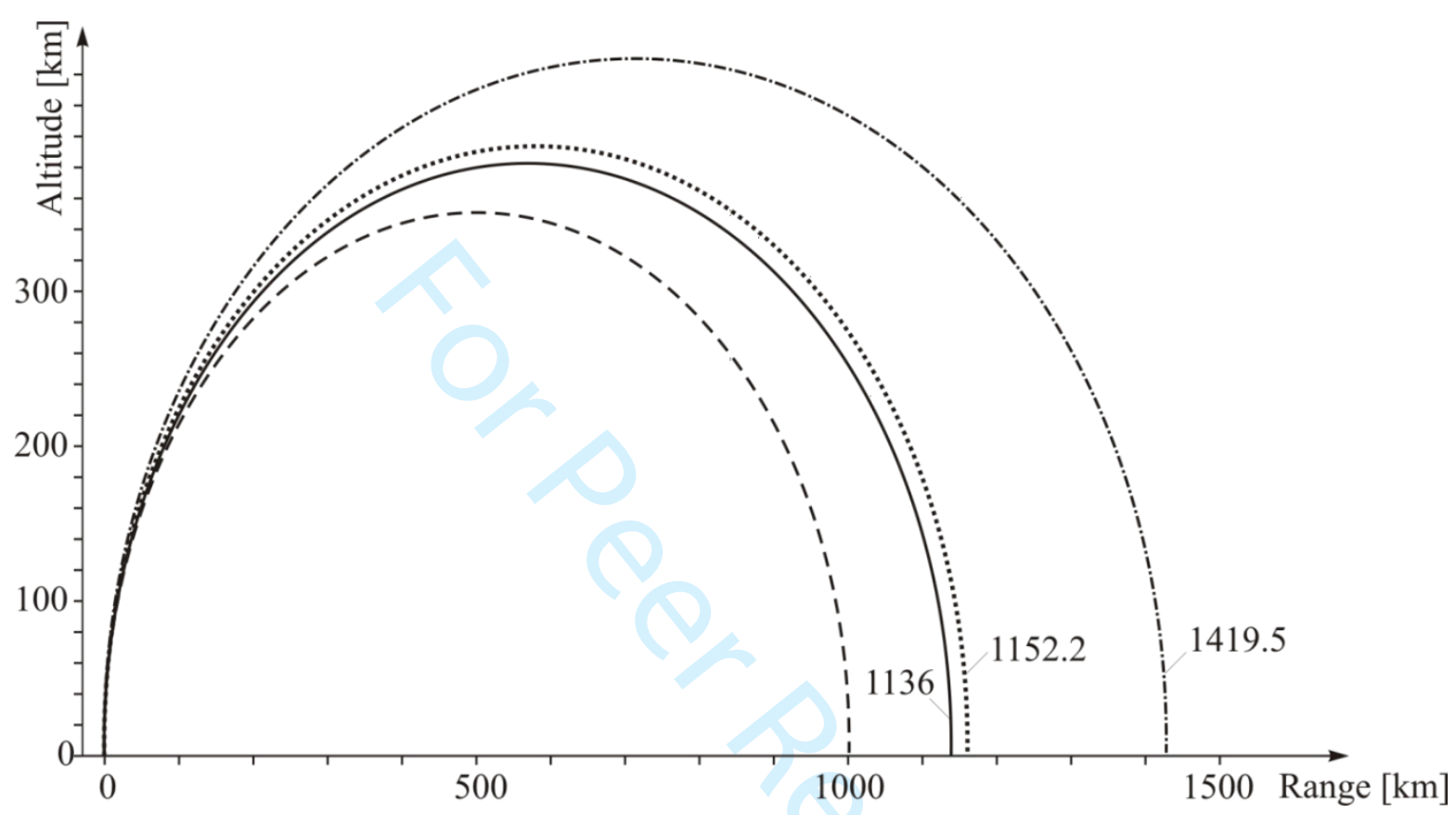

Fig. 23 Ballistic missile range for initial (dashed line) geometry and fsi_o (solid line), ftsi_o (dotted line) and ftsi*_o (dash-dot line) case studies for overall multi-point study 
Table 4 Initial and optimized input/output properties and positive and negative percentage contributions between them

\begin{tabular}{|c|c|c|c|c|c|c|c|c|c|c|c|c|}
\hline Input/output properties & fsi_i [47] & ftsi_i & fsi_o [47] & ftsi_o & ftsi*_o & $\begin{array}{c}\text { ftsi_i } \\
\text { vs. } \\
\text { fsi_i }\end{array}$ & $\begin{array}{c}\text { fsi_o } \\
\text { vs. } \\
\text { fsi_i } \\
\end{array}$ & $\begin{array}{c}\text { ftsi_o } \\
\text { vs. } \\
\text { fsi_o }\end{array}$ & $\begin{array}{c}\text { ftsi }^{*} \text { _o } \\
\text { vs. } \\
\text { fsi_o }\end{array}$ & $\begin{array}{c}\text { ftsi_o } \\
\text { vs. } \\
\text { ftsi_i }\end{array}$ & $\begin{array}{c}\text { ftsi*_o }^{*} \\
\text { vs. } \\
\text { ftsi_i }\end{array}$ & $\begin{array}{c}\text { ftsi*_o }^{*} \\
\text { vs. } \\
\text { ftsi_o }\end{array}$ \\
\hline Fin span: & $0.500[\mathrm{~m}]$ & $0.500[\mathrm{~m}]$ & $0.4171[\mathrm{~m}]$ & $0.4116[\mathrm{~m}]$ & $0.4346[\mathrm{~m}]$ & - & -16.58 & -1.32 & +4.20 & -17.68 & -13.08 & +5.59 \\
\hline Root chord length: & $0.715[\mathrm{~m}]$ & $0.715[\mathrm{~m}]$ & $0.9132[\mathrm{~m}]$ & $0.9895[\mathrm{~m}]$ & $1.0716[\mathrm{~m}]$ & - & +27.72 & +8.36 & +17.35 & +38.39 & +49.87 & +8.30 \\
\hline Tip chord length: & $0.285[\mathrm{~m}]$ & $0.285[\mathrm{~m}]$ & $0.4264[\mathrm{~m}]$ & $0.3291[\mathrm{~m}]$ & $0.3959[\mathrm{~m}]$ & - & +49.61 & -22.82 & -7.15 & +15.47 & +38.91 & +20.30 \\
\hline Angle betw. 1.e. and $z$-axis: & $40.69\left[^{\circ}\right]$ & $40.69\left[^{\circ}\right]$ & $51.2\left[^{\circ}\right]$ & $55.4\left[^{\circ}\right]$ & $51.95\left[^{\circ}\right]$ & - & +25.83 & +8.20 & +1.46 & +36.15 & +27.67 & -6.23 \\
\hline Tip thickness: & $0.0057[\mathrm{~m}]$ & $0.0057[\mathrm{~m}]$ & $0.00291[\mathrm{~m}]$ & $0.00287[\mathrm{~m}]$ & $0.00566[\mathrm{~m}]$ & - & -48.95 & -1.37 & +94.50 & -49.65 & -0.70 & +97.21 \\
\hline Fin mass: & $6.79[\mathrm{~kg}]$ & $6.79[\mathrm{~kg}]$ & $6.78[\mathrm{~kg}]$ & $6.77[\mathrm{~kg}]$ & $8.93[\mathrm{~kg}]$ & - & -0.15 & -0.15 & +31.71 & -0.29 & +31.52 & +31.91 \\
\hline Fin area: & $0.5025\left[\mathrm{~m}^{2}\right]$ & $0.5025\left[\mathrm{~m}^{2}\right]$ & $0.561\left[\mathrm{~m}^{2}\right]$ & $0.548\left[\mathrm{~m}^{2}\right]$ & $0.646\left[\mathrm{~m}^{2}\right]$ & - & +11.64 & -2.32 & +15.15 & +9.05 & +28.56 & +17.88 \\
\hline$F l_{f i n}(M=1.4):$ & $5770.74[\mathrm{~N}]$ & $5753.9[\mathrm{~N}]$ & $5356.34[\mathrm{~N}]$ & $5307.8[\mathrm{~N}]$ & $6094.9[\mathrm{~N}]$ & -0.29 & -7.18 & -0.91 & +13.79 & -7.75 & +5.93 & +14.83 \\
\hline$F d_{\text {fin }}(M=1.4)$ : & $677.73[\mathrm{~N}]$ & $683.72[\mathrm{~N}]$ & $593.57[\mathrm{~N}]$ & $585.08[\mathrm{~N}]$ & $705.38[\mathrm{~N}]$ & +0.88 & -12.42 & -1.43 & +18.84 & -14.43 & +3.17 & +20.56 \\
\hline$F l_{\text {fin }}(M=2.3)$ & $4512.27[\mathrm{~N}]$ & $4520.5[\mathrm{~N}]$ & $4572.49[\mathrm{~N}]$ & $4524.9[\mathrm{~N}]$ & $5304[\mathrm{~N}]$ & +0.18 & +1.33 & -1.04 & +16.00 & +0.10 & +17.33 & +17.22 \\
\hline$F d_{f i n}(M=2.3)$ : & $599.53[\mathrm{~N}]$ & $591.13[\mathrm{~N}]$ & $554.80[\mathrm{~N}]$ & $542.8[\mathrm{~N}]$ & $665.1[\mathrm{~N}]$ & -1.40 & -7.46 & -2.16 & +19.88 & -8.18 & +12.51 & +22.53 \\
\hline$F l_{\text {fin }}(M=4.0)$ : & $2754.21[\mathrm{~N}]$ & $2706.7[\mathrm{~N}]$ & $2978.23[\mathrm{~N}]$ & $2842.7[\mathrm{~N}]$ & $3380.5[\mathrm{~N}]$ & -1.72 & +8.13 & -4.55 & +13.51 & +5.02 & +24.89 & +18.92 \\
\hline$F d_{\text {fin }}(M=4.0)$ & $383.56[\mathrm{~N}]$ & $375.61[\mathrm{~N}]$ & $380.29[\mathrm{~N}]$ & $360.81[\mathrm{~N}]$ & $445.91[\mathrm{~N}]$ & -2.07 & -0.85 & -5.12 & +17.26 & -3.94 & +18.72 & +23.59 \\
\hline$f_{f i n}(M=1.4)$ : & 8.51 & 8.416 & 9.024 & 9.072 & 8.641 & -1.10 & +6.04 & +0.53 & -4.24 & +7.79 & +2.67 & -4.75 \\
\hline$f_{f i n}(M=2.3)$ & 7.53 & 7.647 & 8.242 & 8.336 & 7.975 & +1.55 & +9.45 & +1.14 & -3.24 & +9.01 & +4.29 & -4.33 \\
\hline$f_{\text {fin }}(M=4.0)$ & 7.18 & 7.206 & 7.831 & 7.879 & 7.581 & +0.36 & +9.07 & +0.61 & -3.19 & +9.34 & +5.20 & -3.78 \\
\hline Def. on pos. $3(M=1.4)$ : & $0.02744[\mathrm{~m}]$ & $0.02930[\mathrm{~m}]$ & $0.01785[\mathrm{~m}]$ & $0.01907[\mathrm{~m}]$ & $0.01952[\mathrm{~m}]$ & +6.78 & -34.95 & +6.83 & +9.36 & -34.91 & -33.38 & +2.36 \\
\hline Def. on pos. $7(M=1.4)$ : & $0.02992[\mathrm{~m}]$ & $0.03294[\mathrm{~m}]$ & $0.01788[\mathrm{~m}]$ & $0.01875[\mathrm{~m}]$ & $0.01899[\mathrm{~m}]$ & +10.09 & -40.24 & +4.87 & +6.21 & -43.08 & -42.35 & +1.28 \\
\hline Def. on pos. $3(M=2.3)$ : & $0.02004[\mathrm{~m}]$ & $0.02573[\mathrm{~m}]$ & $0.01389[\mathrm{~m}]$ & $0.01744[\mathrm{~m}]$ & $0.01813[\mathrm{~m}]$ & +28.39 & -30.69 & +25.56 & +30.53 & -32.22 & -29.54 & +3.96 \\
\hline Def. on pos. $7(M=2.3)$ : & $0.02254[\mathrm{~m}]$ & $0.03052[\mathrm{~m}]$ & $0.01826[\mathrm{~m}]$ & $0.02068[\mathrm{~m}]$ & $0.02063[\mathrm{~m}]$ & +35.40 & -18.99 & +13.25 & +12.98 & -32.24 & -32.40 & -0.24 \\
\hline Def. on pos. $3(M=4.0)$ : & $0.01178[\mathrm{~m}]$ & $0.02447[\mathrm{~m}]$ & $0.00862[\mathrm{~m}]$ & $0.01845[\mathrm{~m}]$ & $0.01831[\mathrm{~m}]$ & +107.72 & -26.82 & +114.04 & +112.41 & -24.60 & -25.17 & -0.76 \\
\hline Def. on pos. $7(M=4.0)$ : & $0.01342[\mathrm{~m}]$ & $0.03014[\mathrm{~m}]$ & $0.01211[\mathrm{~m}]$ & $0.02314[\mathrm{~m}]$ & $0.02187[\mathrm{~m}]$ & +124.59 & -9.76 & +91.08 & +80.59 & -23.22 & -27.44 & -5.49 \\
\hline c.p. $(M=1.4)$ : & $5.472[\mathrm{~m}]$ & $5.527[\mathrm{~m}]$ & $5.39[\mathrm{~m}]$ & $5.414[\mathrm{~m}]$ & $5.484[\mathrm{~m}]$ & +1.01 & -1.49 & +0.45 & +1.74 & -2.04 & -0.78 & +1.29 \\
\hline c.p. $(M=2.3)$ : & $4.702[\mathrm{~m}]$ & $4.736[\mathrm{~m}]$ & $4.72[\mathrm{~m}]$ & $4.743[\mathrm{~m}]$ & $4.891[\mathrm{~m}]$ & +0.72 & +0.40 & +0.49 & +3.62 & +0.15 & +3.27 & +3.12 \\
\hline c.p. $(M=4.0)$ : & $3.968[\mathrm{~m}]$ & $3.924[\mathrm{~m}]$ & $4.05[\mathrm{~m}]$ & $3.98[\mathrm{~m}]$ & $4.18[\mathrm{~m}]$ & -1.11 & +2.07 & -1.73 & +3.21 & +1.43 & +6.52 & +5.03 \\
\hline c.g.: & $3.701[\mathrm{~m}]$ & $3.701[\mathrm{~m}]$ & $3.700[\mathrm{~m}]$ & $3.7[\mathrm{~m}]$ & $3.706[\mathrm{~m}]$ & - & 0.00 & +0.00 & +0.16 & -0.03 & +0.14 & +0.16 \\
\hline$f_{\text {missile }}(M=1.4)$ : & 1.74 & 1.699 & 1.778 & 1.748 & 1.917 & -2.36 & +2.18 & -1.69 & +7.82 & +2.88 & +12.83 & +9.67 \\
\hline$f_{\text {missile }}(M=2.3)$ : & 1.50 & 1.482 & 1.586 & 1.577 & 1.719 & -1.20 & +5.73 & -0.57 & +8.39 & +6.41 & +15.99 & +9.00 \\
\hline$f_{\text {missile }}(M=4.0)$ : & 1.60 & 1.569 & 1.691 & 1.662 & 1.775 & -1.94 & +5.69 & -1.71 & +4.97 & +5.93 & +13.13 & +6.80 \\
\hline
\end{tabular}




\section{Conclusion}

The complete study was relied on theoretical demand to establish monolithic numerical framework for FSI/FTSI and MDO purposes. All available experimental results were used for CFD and CSM validation and verification processes in order to assure that numerical FSI/FTSI simulations and numerical optimization could be carried out with minimal lost of accuracy. The procedure of aerodynamic-thermal/structural surrogate-based evolutionary optimization of the SRBM model was carried out within this stable, reliable and flexible numerical multi-modular framework, now with considerably improved performances.

The wind tunnel SRBM model and the real-sized experimental fin model have been separately developed for scientific and internal experimental testing and calibration purposes in Military Technical Institute in Belgrade. These models have been customized for appropriate experimental installations. For the purposes of wind tunnel testing, the SRBM model has been developed with dimensions adapted to the test section dimensions, while for the static structural experiments real-sized experimental fin model has been developed separately. A special kind of contribution was achieved exactly regarding this limitation of the experimental facilities. To be more specific, the used installations have not been equipped with the devices for monitoring of aeroelastic/aerothermoelastic structural responses and they have not been assembled for that purposes. As these installations have not been intended for this kind of testing, creating numerical framework that allows this type of analysis makes a significant upgrade of the overall FSI/FTSI modeling, and consequently overcome this experimental limitation. Furthermore, fin/body interferential problem for scaled missile model was overcome, too, which enables realistic observation of aeroelastic and aerothermoelastic behavior of the fin structure.

In general, the proposed numerical framework ensures precise modeling with high efficiency and high quality of modeled responses of the missile model in critical exploitation phases. The optimization sub environment enabled achieving highly reliable optimal structure with considerably improved performances. Optimizing only aerodynamic shape of the fin structure, significant increase of the range was achieved which places this SRBM type in the category of the medium-range ballistic missiles. This study soundly highlights the necessity for multi-discipline, multi-objective and multi-point analyses of this kind of aircrafts and also justify the need for surrogate-based modeling for that purpose, so consequently it presents aspects, approaches and strategies for conceptual observation of similar aircrafts exposed to the aerodynamic heating. The whole approach ensures significant time and costs reduction of the developing program. What is more, the flexibility of the proposed multi-modular numerical 
framework is contribution for itself, because it can be applied for analyzing different types of phenomena and systems from other scientific and technical fields.

As a future work, this numerical study will be additionally expanded with more robust and realistic optimization process which will be concerned with tri-sonic multi-point problem where instead of standard 27 experimental points, enhanced 53 will be generated.

\section{Acknowledgments}

The authors gratefully acknowledge the support from the Ministry of Education, Science and Technological Development of the Republic of Serbia under the project ON 174004. The author K.M. gratefully acknowledges the support from the Ministry of Education, Science and Technological Development of the Republic of Serbia under the project ON 174001.

\section{References}

[1] Nishikawa, H., “Aerodynamic Heating with Turbulent Flows, AE525 Research Project,” 1994.

[2] Mazzoni, A. J., Filho, J. B. P., and Machado, A. H., "Aerodynamic Heating on VSB-30 Sounding Rocket," Proceedings of the 18th International Congress of Mechanical Engineering, Ouro Preto, Brasil, 2005.

[3] Mahulikar, P. S., "Theoretical Aerothermal Concepts for Configuration Design of Hypersonic Vehicles," Aerospace Science and Technology, Vol. 9, No. 8, 2005, pp. 681-685. doi: 10.1016/j.ast.2005.08.006.

[4] Cayzac, R., Grignon, C., and Carette, E., "Navier-Stokes Computation of Heat Transfer and Aero-Heating Modeling for Supersonic Projectiles," Aerospace Science and Technology, Vol. 10, No. 5, 2006, pp. 374-384. doi: $10.1016 /$ j.ast.2005.12.001.

[5] Liu, J.-x., Hou, Z.-X., Chen, X.-q., and Zhang, J.-t., "Experimental and Numerical Study on the Aero-heating Characteristics of Blunted Waverider,” Applied Thermal Engineering, Vol. 51, No. 1-2, 2013, pp. 301-314. doi: 10.1016/j.applthermaleng.2012.09.026.

[6] Han, X.-Y., and Wang, J., "Effect of Mach Number on Thermoelectric Performance of SiC Ceramics Nose-tip for Supersonic Vehicles," Applied Thermal Engineering, Vol. 62, No. 1, 2014, pp. 141-147. doi: 10.1016/j.applthermaleng.2013.09.011.

[7] Kostoff, N. R., and Cummings, M. R., "Highly Cited Literature of High-Speed Compressible Flow Research," Aerospace Science and Technology, Vol. 26, No. 1, 2013, pp. 216-234.

Review copy- Do not distribute 
doi: 10.1016/j.ast.2012.04.006.

[8] Jiang, Z., Yan, C., Yu, J., Qu, F., and Ma, L., "Effective High-order Solver With Thermally Perfect Gas Model for Hypersonic Heating Prediction," Applied Thermal Engineering, Vol. 99, 2016, pp. 147-159. doi: 10.1016/j.applthermaleng.2015.12.132.

[9] Govindan, S., and Nair, P., "Effect of Numerics and Laminar-turbulent Transition on Heat Flux Distribution Simulation Over a Typical Re-entry Module," Applied Thermal Engineering, Vol. 131, 2018, pp. 849-863.

doi: 10.1016/j.applthermaleng.2017.12.033.

[10] McNamara, J. J., and Friedmann, P. P., "Aeroelastic and Aerothermoelastic Analysis of Hypersonic Vehicles: Current Status and Future Trends," Proceedings of the 14th AIAA/AHI Space Planes and Hypersonic Systems and Technologies Conference, AIAA Paper 2006-8058, 2006.

[11] Dechaumphai, P., Wieting, R. A., and Pandey, K. A., "Fluid-Thermal-Structural Interaction of Aerodynamically Heated Leading Edges," Proceedings of the 30th Structures, Structural Dynamics and Materials Conference, 89-1227-CP, Mobile, AL, U.S.A., 1989, pp. 621-631.

[12] Borreca, S., Cipollini, F., Tumino, G., and Muylaert, J.-M., "Fluid-Structure Thermal Coupling on Expert Open Flaps," Proceedings of the 5th European Symposium on Aerothermodynamics for Space Vehicles, edited by D. Danesy, Cologne, Germany, 2004, pp. 289-294.

[13] Culler, J. A., Crowell, R. A., and McNamara, J. J., "Studies on Fluid-Structural Coupling for Aerothermoelasticity in Hypersonic Flow," Proceedings of the 50th AIAA/ASME/ASCE/AHS/ASC Structures, Structural Dynamics, and Materials Conference, AIAA Paper 2009-2364, May 2009.

[14] Tabiei, A., and Sockalingam, S., "Multiphysics Coupled Fluid/Thermal/Structural Simulation for Hypersonic Reentry Vehicles," Journal of Aerospace Engineering, Vol. 25, No. 2, 2012, pp. 273-281. doi: 10.1061/(ASCE)AS.1943-5525.0000113.

[15] Dasgupta, A., and Neely, J. A., "Fluid-Thermal-Structural Interactions on a Fin in Hypersonic Flow," Proceedings of the 19th Australasian Fluid Mechanics Conference, Melbourne, Australia, 2014.

[16] Pasolini, P., Savino, R., Franco, F., and De Rosa, S., "Preliminary Validation of Fluid-Structure Interaction Modeling for Hypersonic Deployable Re-Entry Systems," Fluid Dynamics and Material Processing, Vol. 11, No. 3, 2015, pp. 301-324. doi: 10.3970/fdmp.2015.011.301.

[17] Guo, S., Xu, J., Qin, Q., and Gu, R., "Fluid-Thermal Interaction Investigation of Spiked Blunt Bodies at Hypersonic Flight Condition," Journal of Spacecraft and Rockets, Vol. 53, No. 4, 2016, pp. 629-643. doi:10.2514/1.A33370. 
[18] Qin, Q., Xu, J., Guo, S., "Fluid-thermal analysis of aerodynamic heating over spiked blunt body configurations," Acta Astronautica, Vol. 132, 2017, pp. 230-242.

doi: 10.1016/j.actaastro.2016.12.037.

[19] Persova, G. M., Soloveichik, G. Y., Belov, K. V., Kiselev, S. D., Vagin, V. D., Domnikov, A. P., Patrushev, I. I., and Kurskiy, N. D., "Modeling of Aerodynamic Heat Flux and Thermoelastic Behavior of Nose Caps of Hypersonic Vehicles," Acta Astronautica, Vol. 136, 2017, pp. 312-331.

doi: 10.1016/j.actaastro.2017.02.021.

[20] Chen, F., Zhang, S., and Liu, H., "Modeling and Analysis of Fluid-Thermal-Structure Coupling Problems for Hypersonic Vehicles,” edited by R. K. Agarwal, Advances in Some Hypersonic Vehicles Technologies, IntechOpen, 2018, pp. 111-131.

[21] Deepak, R. N., Ray, T., and Boyce, R. R., "Evolutionary Algorithm Shape Optimization of a Hypersonic Flight Experiment Nose Cone," Journal of Spacecraft and Rockets, Vol. 45, No. 3, 2008, pp. 428-437. doi: $10.2514 / 1.33826$.

[22] Theisinger, E. J., and Braun, D. R., "Multi-Objective Hypersonic Entry Aeroshell Shape Optimization," Journal of Spacecraft and Rockets, Vol. 46, No. 5, 2009, pp. 957-966. doi: $10.2514 / 1.41136$.

[23] Deng, F., Jiao, Z., Chen, J., Zhang, D., and Tang, S., "Overall Performance Analysis-Oriented Aerodynamic Configuration Optimization Design for Hypersonic Vehicles,” Journal of Spacecraft and Rockets, Vol. 54, No. 5, 2017, pp. 1015-1026. doi: 10.2514/1.A33729.

[24] Lesieutre, J. D., Dillenius, F. E. M., and Lesieutre, O. T., "Multidisciplinary Design Optimization of Missile Configurations and Fin Planforms for Improved Performance," Proceedings of the 7th Symposium on Multidisciplinary Analysis and Optimization, AIAA Paper 98-4890, September 1998.

[25] Schönning, A., Nayfeh, J., and Zarda, R., “An Integrated Design and Optimization Environment for Industrial Large Scaled Systems," Research in Engineering Design, Vol. 16, No. 1-2, 2005, pp. 86-95. doi: 10.1007/s00163-005-0006-y.

[26] Tanıl, Ç., Platin, E. B., and Mahmutyazıcıŏglu, G., "External Configuration Optimization of Missiles in Conceptual Design," Proceedings of the AIAA Atmospheric Flight Mechanics Conference, AIAA Paper 2009-5719, August 2009.

[27] Yang, R. Y., Jung, K. S., Cho, H. T., and Myong, S. R., “An Aerodynamic Shape Optimization Study to Maximize the Range of a Guided Missile," Proceedings of the 28th AIAA Applied Aerodynamics Conference, AIAA Paper 2010-4240, June-July 2010. 
[28] Lisk, D., Robinson, T., and Robinson, D., "Multi-Objective Optimization of Supersonic Projectiles Multi-Objective Optimization of Supersonic Projectiles," Proceedings of the 48th AIAA Aerospace Sciences Meeting Including the New Horizons Forum and Aerospace Exposition, AIAA Paper 2010-1500, January 2010.

[29] Dyer, D. J., Hartfield, J. R., Dozier, V. G., and Burkhalter, E. J., “Aerospace Design Optimization Using a Steady State Real-coded Genetic Algorithm,” Applied Mathematics and Computation, Vol. 218, No. 9, 2012, pp. 4710-4730. doi: 10.1016/j.amc.2011.07.038.

[30] Badyrka, M. J., Hartfield, J. R., and Jenkins, M. R., “Aerospace Design Optimization Using a Compound Repulsive Particle Swarm," Applied Mathematics and Computation, Vol. 219, No. 15, 2013, pp. 8311-8331. doi: 10.1016/j.amc.2012.10.113.

[31] Riddle, B. D., Hartfield, J. R., Burkhalter, E. J., and Jenkins, M. R., "Genetic Algorithm Optimization of Liquid Propellant Missile Systems," Proceedings of the 45th AIAA Aerospace Sciences Meeting and Exhibit, AIAA Paper 2007-362, January 2007.

[32] Riddle, B. D., Hartfield, J. R., Burkhalter, E. J., and Jenkins, M. R., Genetic-Algorithm Optimization of LiquidPropellant Missile Systems, Journal of Spacecraft and Rockets, Vol. 46, No. 1, 2009, pp. 151-159. doi: $10.2514 / 1.30891$.

[33] Zhu, H., Liu, L., Zhou, S. and Li, Y., "Integrated Aerodynamic Thermal Structure Design Optimization Method of Lifting Surfaces," Journal of Aircraft, Vol. 5, No. 49, 2012, pp. 1521-1526. doi: $10.2514 / 1 . C 031464$.

[34] Verstraete, D., Sharifzadeh, S., and Hendrick, P., "Definition and Aero-Elastic Optimisation of the Structure of the Lapcat A2 Mach 5 Airliner," Proceedings of the 28th International Congress of the Aeronautical Sciences, Vol. 3, Brisbane, Australia, 2012, pp. 2191-2199.

[35] Munk, J. D., Vio, A. G., and Steven, P. G., “Aerothermoelastic Structural Topology Optimisation for a Hypersonic Transport Aircraft Wing," Proceedings of the 11th World Congress on Structural and Multidisciplinary Optimization, Sydney, Australia, 7-12 June 2015.

[36] Du, Z., Wan, Z., and Yang, C., "Robust Aeroelastic Design Optimization of Hypersonic Wings Considering Uncertainty in Heat Flux," Transactions of Japan Society for Aeronautical and Space Sciences, Vol. 60, No. 3, 2017. doi: $10.2322 /$ tjsass.60.152.

[37] Design Modeler User's Guide, Release 19.1, ANSYS, Inc., April 2018.

[38] ANSYS Meshing User's Guide, Release 19.1, ANSYS, Inc., April 2018.

[39] ANSYS Fluent Theory Guide, Release 19.1, ANSYS, Inc., April 2018.

[40] ANSYS Fluent User's Guide, Release 19.1, ANSYS, Inc., April 2018. 
[41] Menter, R. F., “Two-Equation Eddy-Viscosity Turbulence Models for Engineering Applications,” AIAA Journal, Vol. 32, No. 8, 1994, pp. 1598-1605.

doi: $10.2514 / 3.12149$.

[42] Menter, R. F., "Improved Two-Equation k- $\omega$ Turbulence Models for Aerodynamic Flows,” NASA-TM-103975,1992.

[43] Menter, R. F., Kuntz, M., and Langtry, R., "Ten Years of Industrial Experience with the SST Turbulence Model," Turbulence, Heat and Mass Transfer 4, edited by K. Hanjalić, Y. Nagano and M. Tummers, Begell House, Inc., New York, Wallingford, 2003, pp. 625-632.

[44] Menter, R. F., "Review of the shear-stress transport turbulence model experience from an industrial perspective," International Journal of Computational Fluid Dynamics, Vol. 23, No. 4, 2009, pp. 305-316. doi: $10.1080 / 10618560902773387$.

[45] Menter, F., Ferreira, C. J., Esch, T., and Konno, B., “The SST Turbulence Model with Improved Wall Treatment for Heat Transfer Predictions in Gas Turbines," Proceedings of the International Gas Turbine Congress, IGTC2003-TS-059, Tokyo, Japan, 2003.

[46] Menter, R. F., "Performance of Popular Turbulence Models for Attached and Separated Adverse Pressure Gradient Flows," AIAA Journal, Vol. 30, No. 8, 1992, pp. 2066-2072. doi: $10.2514 / 3.11180$.

[47] Vidanović, N., Rašuo, B., Kastratović, G., Maksimović, S., Curčić, D., and Samardžić, M., "Aerodynamic-structural missile fin optimization,” Aerospace Science and Technology, Vol. 65, 2017, pp. 26-45. doi: 10.1016/j.ast.2017.02.010.

[48] ANSYS Mechanical User's Guide, Release 19.1, ANSYS, Inc., April 2018.

[49] ANSYS Mechanical APDL Theory Reference, Release 19.1, ANSYS, Inc., April 2018.

[50] Xie, G., Wang, Q., Sunden, B., and Zhang, W., “Thermomechanical Optimization of Lightweight Thermal Protection System Under Aerodynamic Heating," Applied Thermal Engineering, Vol. 59, No. 1-2, 2013, pp. 425-434. doi: 10.1016/j.applthermaleng.2013.06.002.

[51] System Coupling User's Guide, Release 19.1, ANSYS, Inc., April 2018.

[52] Batina, T. J., "Unsteady Euler Airfoil Solutions Using Unstructured Dynamic Meshes,” AIAA Journal, Vol. 28, No. 8, 1990, pp. 1381-1388. doi: $10.2514 / 3.25229$.

[53] Robinson, A. B., Batina, T. J., and Yang, T. Y. H., "Aeroelastic Analysis of Wings Using the Euler Equations with a Deforming Mesh,” Journal of Aircraft, Vol. 28, No. 11, 1991, pp. 781-788. doi: $10.2514 / 3.46096$. 
[54] Jansen, K., Shakib, F., and Hughes, T., "Fast Projection Algorithm for Unstructured Meshes," Computational Nonlinear Mechanics in Aerospace Engineering, edited by S. Atluri, Progress in Astronautics and Aeronautics, AIAA, Washington, DC, 1992, pp. 175-204.

[55] Galpin, F. P., Broberg, B. R., and Hutchinson, R. B., “Three-Dimensional Navier Stokes Predictions of Steady-State Rotor/Stator Interaction with Pitch Change," Proceedings of the 3rd Annual Conference of the CFD Society of Canada, Banff, Alberta, Canada, June 1995.

[56] Design Exploration User's Guide, Release 19.1, ANSYS, Inc., April 2018.

[57] Myers, H. R., Montgomery, C. D., and Anderson-Cook, M. C., Response surface methodology, Process and Product Optimization Using Designed Experiments, John Wiley \& Sons, Inc., 2009.

[58] Deb, K., Multi-Objective Optimization using Evolutionary Algorithms, John Wiley \& Sons Ltd., 2001.

[59] Deb, K., Pratap, A., Agarwal, S., and Meyarivan, T., “A Fast and Elitist Multiobjective Genetic Algorithm: NSGA-II,” IEEE Transactions on Evolutionary Computation, Vol. 6, No. 2, 2002, pp. 182-197. doi: $10.1109 / 4235.996017$.

[60] Deb, K., and Tiwari, S., "Omni-optimizer: A generic evolutionary algorithm for single and multi-objective optimization," European Journal of Operational Research, Vol. 185, No. 3, 2008, pp. 1062-1087. doi: 10.1016/j.ejor.2006.06.042.

[61] Deb, K., "An efficient constraint handling method for genetic algorithms," Computer Methods in Applied Mechanics and Engineering, Vol. 186, No. 2-4, 2000, pp. 311-338. doi: 10.1016/S0045-7825(99)00389-8.

[62] Shukla, K. P., and Deb, K., "On finding multiple Pareto-optimal solutions using classical and evolutionary generating methods," European Journal of Operational Research, Vol. 181, No. 3, 2007, pp. 1630-1652. doi: 10.1016/j.ejor.2006.08.002.

[63] Deb, K., and Goel, T., "Controlled Elitist Non-dominated Sorting Genetic Algorithms for Better Convergence," Proceedings of the 1st International Conference on Evolutionary Multi-Criterion Optimization, edited by E. Zitzler, L. Thiele, K. Deb, C. A. C. Coello, D. Corne, Zurich, Switzerland, 2001, pp. 67-81.

[64] Srinivas, N., and Deb, K., "Multi-objective function optimization using non-dominated sorting genetic algorithms," Evolutionary Computation, Vol. 2, No. 3, 1994, pp. 221-248. doi: 10.1162/evco.1994.2.3.221.

[65] Vidanović, D. N., Rašuo, P. B., Damljanović, B. D., Vuković, S. Đ., and Ćurčić, S. D., "Validation of the CFD code used for determination of aerodynamic characteristics of nonstandard AGARD-B calibration model," Thermal Science, Vol. 18, No. 4, 2014, pp. 1223-1233. 
doi: 10.2298/TSCI130409104V.

[66] Vidanović, D. N., “Aerodynamic-structural optimization of aircraft lifting surfaces,” Ph.D. Dissertation, (in Serbian), Faculty of Mechanical Engineering, University of Belgrade, Belgrade, Serbia, 2015.

[67] Belaidouni, H., Samardžić, M., Živković, S., and Kozić, M., “Computational Fluid Dynamics and Experimental Data Comparison of a Missile-Model Roll Derivative,” Journal of Spacecraft and Rockets, Vol. 54, No. 3, 2017, pp. 672-682. doi: $10.2514 / 1 . A 33674$

[68] Rašuo, B., Aircraft Production Technology, (in Serbian), Faculty of mechanical engineering, University of Belgrade, Belgrade, Serbia, 1995.

[69] Glover, S. L., and Hagan, C. J., “The Motion of Ballistic Missile,” AD0731662, Applied Physics Laboratory, The Johns Hopkins University, 1971. 